
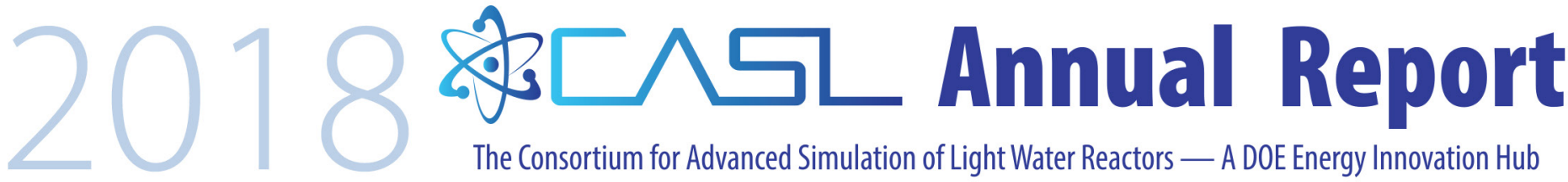

The Consortium for Advanced Simulation of Light Water Reactors — A DOE Energy Innovation Hub

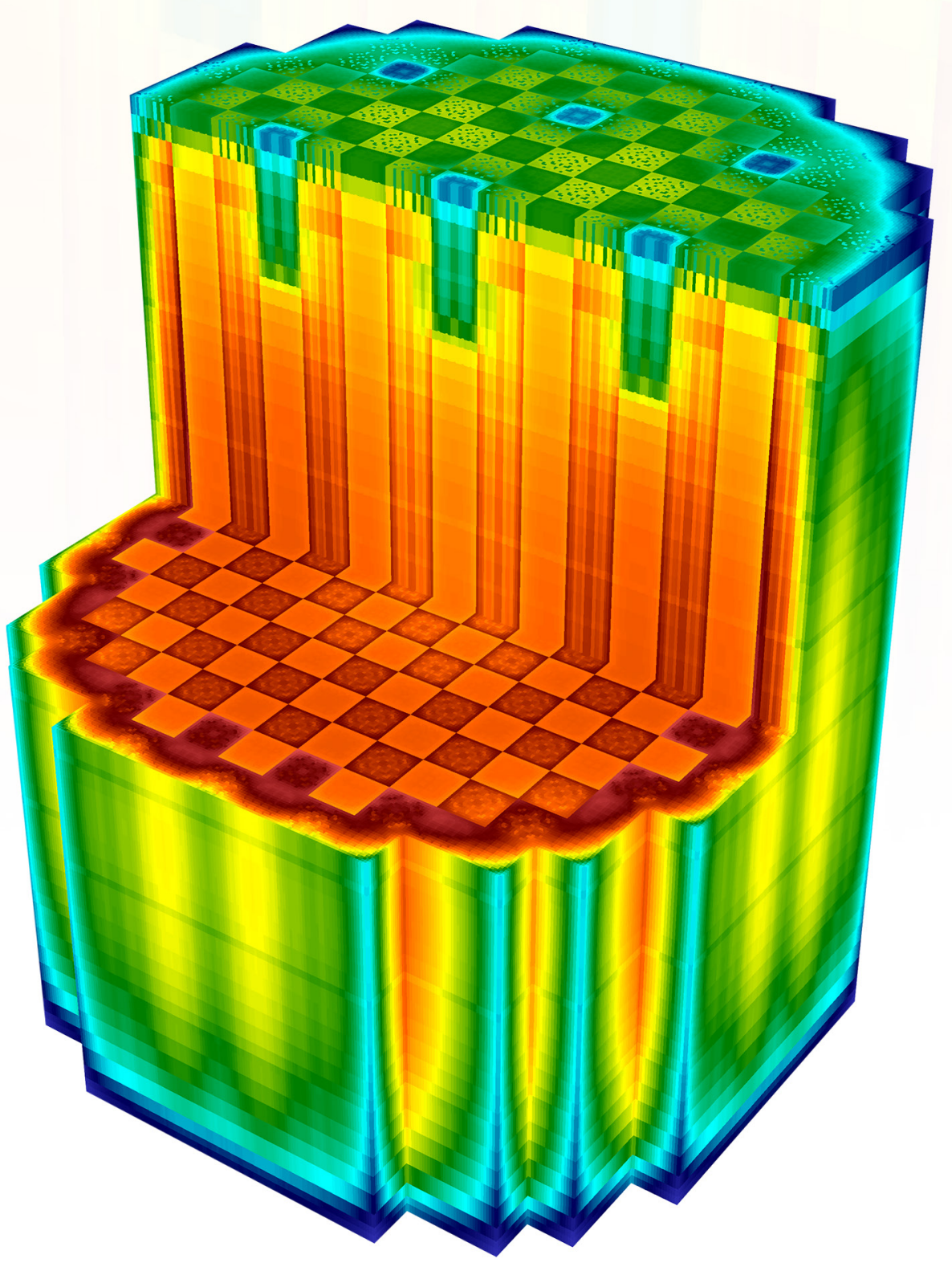


DOCUMENT AVAILABILITY

Reports produced after (DOE) SciTech Connect.

Website www.osti.gov

Reports produced before January 1, 1996, may be purchased by members of the public from the following source:

National Technical Information Service

5285 Port Royal Road

Telephone 703-605-6000 (1-800-553-6847)

TDD 703-487-4639

Fax 703-605-6900

Website http://classic.ntis.gov

Reports are available to DOE employees, DOE contractors, Energy Technology Data Exchange representatives, and International Nuclear Information System representatives from the following source

Office of Scientific and Technical Information

PO Box 62

Oak Ridge, TN 37831

Telephone $865-576-840$
Fax 865-576-5728

E-mail reports@ostigov

Website http://www.osti.gov/contact.htm

This report was prepared as an account of work sponsord by an agency of the United States Government. Neither the United States Government nor any agency thereof, nor any of their employees,
makes any warranty, express or implied, or assumes any legal liability or responsibility for the accuracy, completeness, or usefulness of any information, apparatus, product, or process disclosed, or represents that its use would not infringe privately owned rights. Reference herein to any specific commercial product, process, or service by trade name, or imply its endorsement, recommendation, or favoring by the United States Government or any agency thereof. The views and opinions of authors expressed herein do not necessarily state or reflect those of the United States Government or any agency thereo

\section{Cover image:}

CASL Virtual Environment for Reactor

Applications (VERA) predictions of

transient Xenon-135 distribution during

startup of Tennessee Valley Authority's

Watts Bar Unit 2 Nuclear Plant at 28\% of

full operating power. Xenon-135 is an

important radionuclide to simulate given

its strong absorption of neutrons and

associated impact on reactor operating

behavior.

\section{MESSAGE FROM THE CASL DIRECTOR}

On behalf of CASL, I am pleased to present this annual report for fiscal year 2018, which provides a summary of achievements and impacts in the areas of research and development technology deployment, education, and workforce development. The Virtual Environment for Reactor Applications (VERA) continues to mature as an integrated, high-performance computing platform for performing multiphysics simulation for advanced nuclear reactor technologies. While significant progress has been made on the solution of CASL challenge strate new capabilities made possible within VERA. Most notable is the integration of excor modeling capabilities that have enabled first-of-a-kind analysis beyond the reactor core. This has expanded the potential range of VERA applications to include areas such as reactor material component damage, which is important to reactor operations and plant lifetime extension.

The unique partnerships within CASL bring together a diverse team of talented individuals working in a collaborative environment across national laboratories, academia, and industry. The key to such collaboration is having a shared vision, a line of sight from each individual contributor and from each technical focus area toward common goals, and excellence in execulon. As CASL approachesthe focus area toward common gols, and a do a focus on providing the knowledge and technology transfer to industry to assure that codes are, in the words of the CASL Industry Council, "used and useful." Examples outlined in the report include VERA applications for the NuScale and AP1000 advanced light ( Whe excore

As CASL Director and former Chief Scientist, I am inspired by the strength and breadth of technical talent with whom I have had the pleasure of working. I recognize the CASL Board of Directors, chaired by former US Department of Energy (DOE) Deputy Assistant Secretary and NRC Commissioner Dr. Pete Lyons, who have provided invaluable input and feedback on CASL activities. The CASL Ccience Council, chaired by Dr. Bill Oberkampi, continues to provide valuable technical insights that have been incorporated into our St. Clair, both of Duke Energy, whose ongoing efforts will assure a VERA end product that can and will be adopted by industry. CASL continues to receive strong support from DOE's Office of Nuclear Energy (NE), including Shane Johnson, Deputy Assistant Secretary for Reactor Fleet and Advanced Reactor Deployment, and Tom Miller, Alice Caponiti, Dan Funk, and David Henderson of federal program leadership.

I would like to acknowledge the leadership of Dr. Jess Gehin, who left the position of CASL Director and accepted a senior leadership position at Idaho National Laboratory (INL). Jess was involved in CASL from the beginning and has provided outstanding contributions throughout his time with CASL.I also appreciate the leadership of Dr. Kevin Clarno, who served as acting CASL Director during the transition period. I want to thank Dr. Jim Wolf and Dr. Rich Martineau for their leadership as CASL Deputy Director, both of whom have moved on to other key roles at INL, and his replacement, Dr. Jason Hales, who has extensive experience in ATF and currently leads the fer chief scientist position.

To date, CASL has simulated 152 operating fuel cycles across 21 reactors, representing the full spectrum of pressurized water reactors

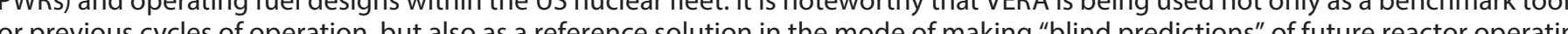
behavior. Primary examples are the simulations of Watts Bar 2, which achieved initial criticality in May 2016, and Sanmen 1 and 2. which achieved initial criticality in June and August 2018, respectively. In all instances, VERA predictions showed excellent agreement with both global and local measured data for first-of-a-kind core designs. This is a key landmark in terms of establishing VERA as an advanced modeling and simulation platform that can predict with high confidence.

Fiscal year 2018 has been a very productive year for CASL, and I look forward to continuing the high level of performance and commitment that has made CASL a success.

Sincerely,

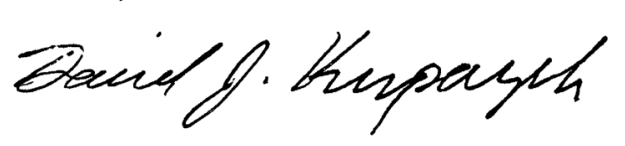

Dr. David J. Kropacz 
THE CONSORTIUM FOR ADVANCED SIMULATION OF

\section{FOUNDING PARTNERS}

Oak Ridge National Laboratory

Idaho National Laboratory

Los Alamos National Laboratory

Sandia National Laboratory

University of Michigan

North Carolina State University

Electric Power Research Institute

Tennessee Valley Authority

Westinghouse Electric Company

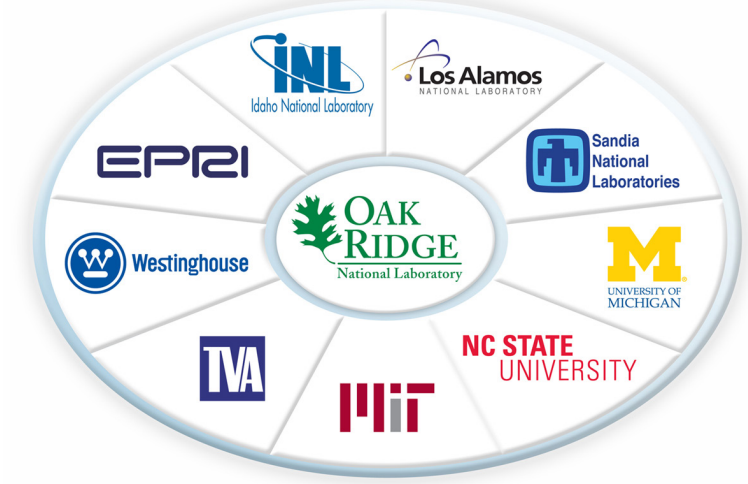

\section{CONTRIBUTING PARTNERS}

Ansys, Inc.

Arizona Public Service

ASCOMP AG

Battelle

Babcock \& Wilcox

BWXT Technologies, Inc.

City College of New York

Core Physics Inc.

Dassault Systems

Dominion

Duke Energy

Enercon

Exelon Corporation

Florida State University

Framatome

GSE Systems

Global Nuclear Fuel LLC

Imperial College

Johns Hopkins University

NuScale Power

Pensechnic Institute

University of Texas at Austin LIGHT WATER REACTORS

Massachusetts Institute of Technology
Oregon State University

Pacific Northwest National Laboratory Pennsylvania State University Purdue University Siemens

Southern Company

Studsvik Scandpower

Structural Integrity Associates, Inc.

Texas A\&M University

University of California Los Angeles

University of California Santa Barbara

University of Florida

University of Notre Dame

University of Tennessee - Knoxville

University of Tennessee - Chattanoog

University of Wisconsin

\section{CONTENTS}

CASL Director Statement

Founding and Contributing Partners ....

Figures......

Acronyms.............

PART 1: FY18 OVERVIEW

Introduction

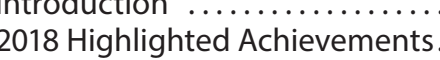

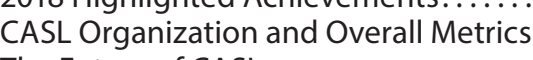

The Future of CASL.

PART 2: SCIENCE AND ENGINEERING PROGRESS AND IMPACT

Development and Advancement of VERA

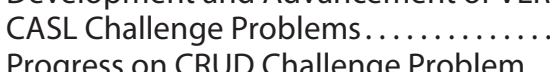

Progress on CRUD Challenge Problem .......
Progress on the DNB Challenge Problem

Progress on the PCI Challenge Problem

Progress on LOCA Challenge Problem....

PART 3: END USER IMPACT AND NUCLEAR INDUSTRY ENGAGEMENT

Application of VERA to Operating Plants.....

Industry Use of CASL Tools

CASL Technology Transfe...

CASL Training and Workshops........

Engagement with the NRC

CASL Education Program...

PART 4: RETURN ON FY18 TAXPAYER INVESTMENT

FY18 Financial Performance....

DOE Reportable Milestones

CONCLUSIONS .

ACKNOWLEDGMENTS

26 


\section{FIGURES}

Figure 1. Seabrook Cycle 5 distribution of the maximum corrosion thicknesses..................... Figure 2. Validation of CFD critical heat flux predictive capability (non-mixing vane grid [NMVG])........ 2 Figure 3. VERA detailed power distribution for the AP1000 at the limiting DNB condition (hot zero power

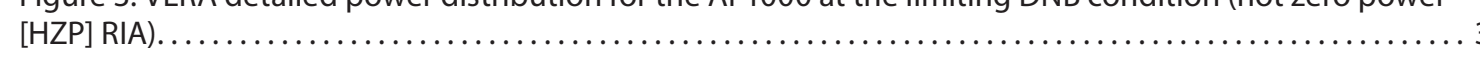
Figure 4. Watts Bar Nuclear Unit 1 (WBN1) Cycle 8 thermal neutron flux and accumulated vessel fluence... 3 Figure 5. NuScale SMR design flow circulation........................................... 4

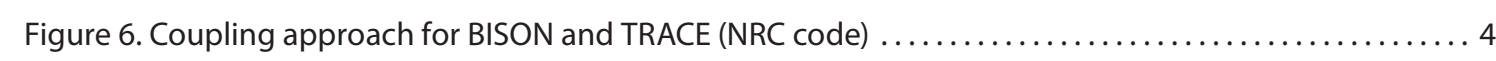

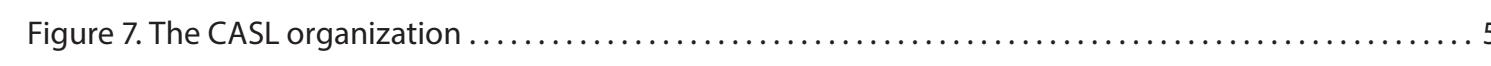

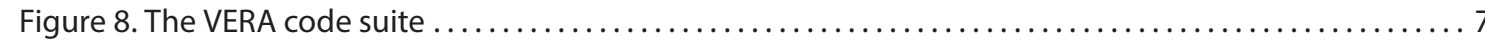
Figure 9. Example of VERAView vessel fluence calculation visualization ............................ Figure 10. Summary of the CASL challenge problem scope ................................... 10 Figure 11. Boiling curve comparison and DNB detection for different surfaces.................... 11 Figure 12. BISON calculated cladding hoop stress and gap width evolution for the AP1000 RIA simulation 12

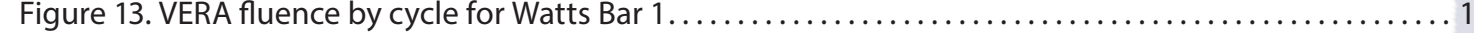
Figure 14. Subcritical thermal neutron flux in WBN1 cycle 8 when fully loaded ..................... 16 Figure 15. TOPFUEL 2018 publication on "Industry Use of CASL Tools" .......................... Figure 16. VERA licenses issued to individuals by organization ............................... 17

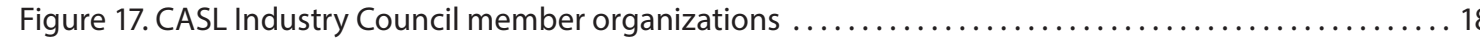
Figure 18. CASL Industry Council meeting, Asheville, North Carolina, April 10-11, $2018 \ldots \ldots \ldots \ldots \ldots \ldots 18$

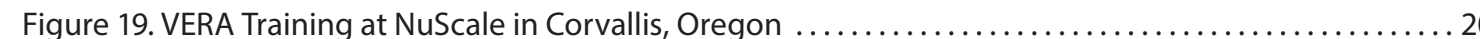
Figure 20. Excore neutron transport calculations workshop at ORNL.......................... 20 Figure 21. CASL and NRC collaboration program plan .................................... 2 Figure 22. CASL student Joseph Cambareri (NCSU) explaining his research at the American Nuclear Society
(ANS) Student Conference poster session................................................. 21

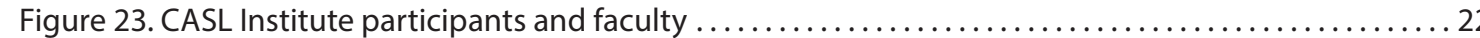

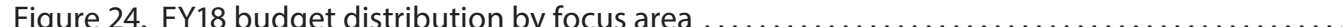

\section{TABLES}

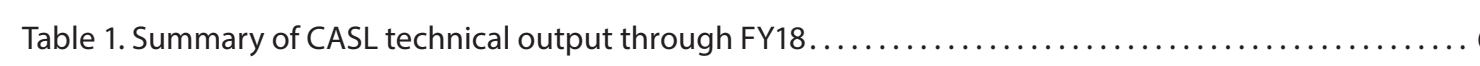

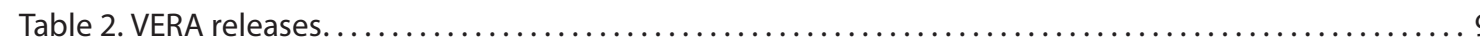
Table 3. BISON-calculated burst test results for ANL experiments (OCL-5, OCL-8 and OCL-11) . . . . . . . 13

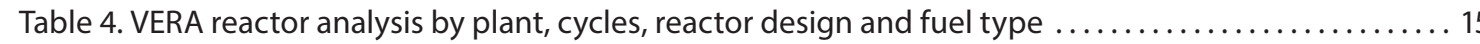
Table 5. Industry Council survey responses on VERA use .....................................

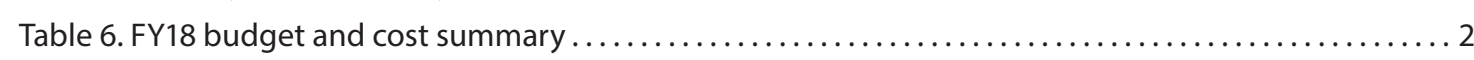

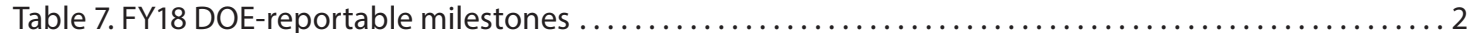

\section{ACRONYMS}

ALCC ASCR Leadership Computing Challenge Advanced Modeling Application Focus Area Argonne National Laboratory American Nuclear Society

Advanced Scientific Computing Research accident-tolerant fuel

boiling water reactor full bundle tests Babcock and Wilcox

boiling water reactor

Consortium for Advanced Simulation of Light Water Reactors computational fluid dynamics

crud-induced localized corrosion

crud-induced power shift

comprehensive reactor analysis bundle

development and deployment departure from nucleate boiling

US Department of Energy

DOE Office of Nuclear Energy

Electric Power Research Institute

excore applications

Fuels Materials Chemistry Focus Area

fiscal year

grid-to-rod fretting

high burnup structure

hot full power

high-performance computing

hot zero power

inverse count rate ratio

instrumented fuel assembly

Idaho National Laboratory

Knolls Atomic Power Laboratory

loss-of-coolant accident

LBLOCA large-break loss-of-coolant accident

LWR light water reactor

MVG mixing vane grid

M\&S modeling and simulation

NCSU North Carolina State University

NEAMS Nuclear Energy Advanced Modeling and Simulation

NMVG non-mixing vane grid

NRC US Nuclear Regulatory Commission 
out of cell

Oak Ridge National Laboratory

pellet-clad interaction

PCMM Predictive Code Maturity Mode

research and development

Research Experiences for Undergraduates

reactivity-initiated accident

Radiation Safety Information Computational Center

Radiation Transport Methods Focus Area

small modular reactor

Special Power Excursion Reactor Test

test and evaluation

Thermal Hydraulics Methods Focus Area

Tennessee Valley Authority

University of Illinois at Urbana-Champaign

University of Tennessee, Knoxville

verification and validation

Virtual Environment for Reactor Application

Virtual Environment for Reactor Applications - Core Simulator

VERA Users Group

Verification and Validation Implementation Focus Area

Watts Bar Nuclear Unit 1

Watts Bar Nuclear Unit 2

Westinghouse Electric Company

extended finite element method

\section{PART 1: FY18 OVERVIEW}

\section{INTRODUCTION}

The Consortium for Advanced Simulation of Light Water Reactors (CASL) was established in July 2010 as the first US Department of Energy (DOE) Energy Innovation Hub, simulation (M\&S) tools that can be used to analyze issues associated with the operation of US commercial light water reactors (LWRs). During this period, the program focused primarily on capabilities to solve challenges related to pressurized water reactor (PWR) operation. In January 2015, the program was extended for an additional five years with the goal of finalizing development and deployment of CASL tools for PWR analysis an extending the program 's tools for use in small modular reactor (SMR) operation and rized to receive additional funds to focus on the use of advanced M\&S tools in a requla tory environment.

The CASL program's vision statement has remained constant over its period of operations:

To predict with confidence the performance and assured safety of nuclear reactors, throug comprehensive, science-based M\&S technology deployed and applied broadly by the US

To achieve this vision, CASL must:

- Promote an enhanced scientific basis and understanding of reactor operations by

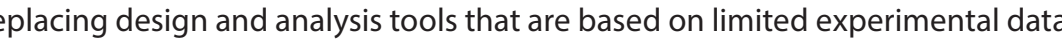
with more robust science-based predictive capabilities;

tools;

- Incorporate uncertainty quantification into the M\&S environment development process;

- Educate today's industry professionals in the use of advanced M\&S tools through direct engagement in CASL activities, and develop the next generation of engneers through use of appropriate curricula at partner universities; and

- Engage the US Nuclear Regulatory Commission (NRC) to help facilitate eventual industry use of the CASL tools to support licensing.

The continuing success of the CASL program is driven by the unique partnerships developed among world-class scientists and engineers across the nuclear industry, national laboratories, and academia. In FY18, CASL engaged nearly 350 people in a coordinated, focused effort to advance the state of the art in advanced M\&S tools and capabilities and to drive technology deployment for the benefit of the US nuclear industry. 


\section{HIGHLIGHTED ACHIEVEMENTS}

Fiscal year (FY) 2018 was another productive year for CASL that saw a maturation of the CASL completed by the program during the year are described below:

\section{VERA Crud-Induced Localized Corrosion (CILC) Modeling Capability}

CILC remains a challenge for reactor operation and remains a limiting design constrain for PWR reactors. An advanced CILC screening capability (R. Salko et al. 2018) has corrosion evolution during the fuel cycle. The work focused on the development and implementation of advanced models for crud buildup coupled with higher resolution computational fluid dynamics (CFD)-informed thermal-hydraulic detail. This first-of-akind capability allows the capture of fuel rod azimuthal flow effects due to grids and spacers on corrosion. A three-dimensional full core analysis was performed by running calculated corrosion thickness at each axial level.

2. Advancement of Computational Fluid Dynamics (CFD) Two-Phase Flow Modeling

The prediction of boiling and critical heat flux within CFD is highly dependent on the physical modeling of mechanisms for vapor generation and bubble hydrodynamic behavior that are encompassed by CFD closure relations. Examples of advanced CASL capabilities include new models for heat flux partitioning, lateral void redistribution, near-wall bubble interaction effects, and bubble-induced turbulence. In FY18 these closure models were extensively validated against a range of two-phase flow nucleate boiling (DNB) framework (E. Baglietto et al. 2018) Validation of CFD-predicted critical heat flux results for non-mixing vane grid (NMVG) and mixing vane grid (MVG) spacers demonstrate significant progress toward a fully predictive DNB capability.

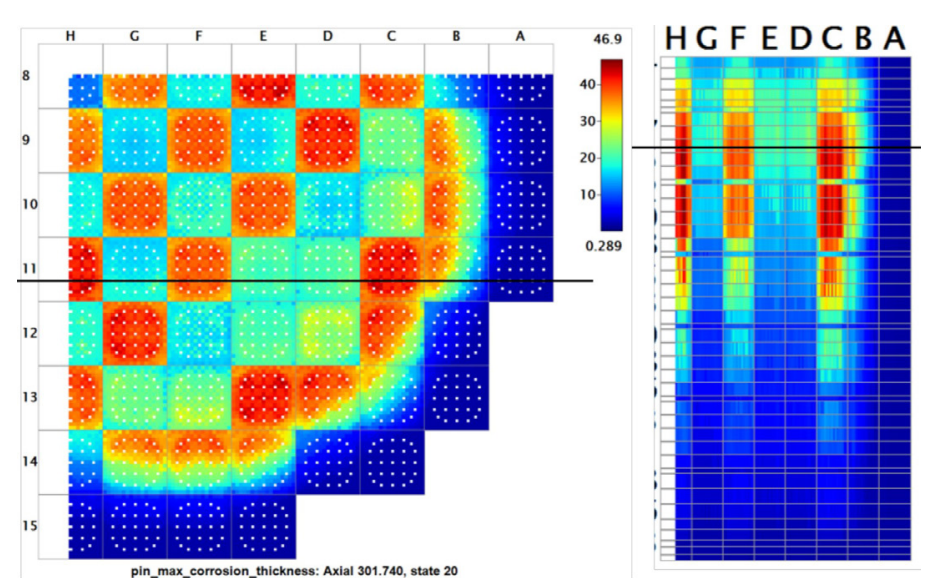

Figure 1. Seabrook Cycle 5 distribution of the maximum corrosion thicknesses
CFD vs Exp. on DNB for NMVG

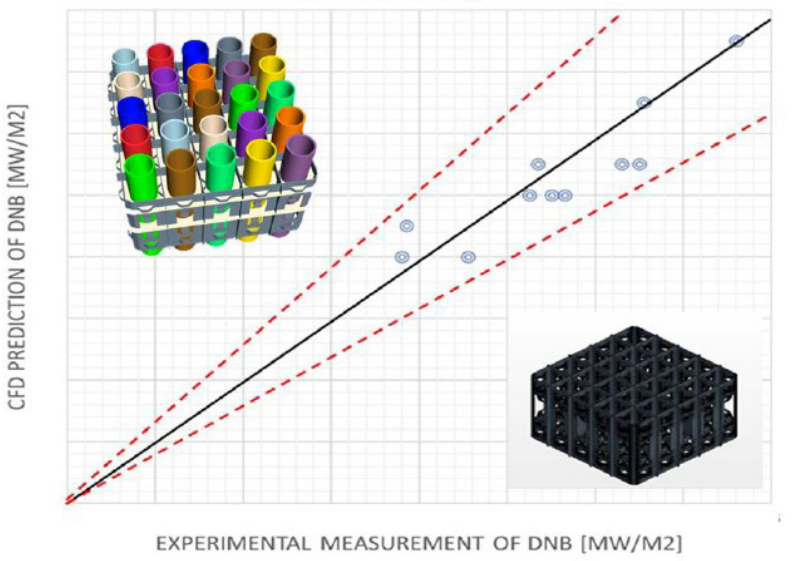

Figure 2. Validation of CFD critical heat flux predictive capability (non-mixing vane grid [NMVG])
3. Development, Validation, and Demonstration of VERA for the Reactivity-Initiated Accident (RIA)

CASL has developed a transient three-dimensional VERA capability applicable to safety analyses such as the reactivity-initiated purpose is to obtain a pin-resolved higher-fidelity M\&S capability than that currently used by the industry in NRC-approved codes and methodologies (G. Swindlehurst 2018). VERA analyses for the AP1000 were demonstrated for the conditions of peak enthalpy and critical heat nux (mingications of the CAring the post-peak bilities are expected to be implementation in reference capations, determination of margins to regulatory figures of merit, evaluation of RIA test results, provision of simulation results to fill gaps in the RIA experimental testing database, and potentially

replacement or augmentation of licensing methodologies.

4. VERA Excore Radiation Transport Capability Development Recent advancements made by CASL have resulted in a new capability based on coupling the Shift continuous-energy solver within VERA. This has resulted in a novel first-o core solver within VERA. This has resulted in a novel, first-of-a-kind flux and fluence in regions of commercial reactors well outside the reactor core. This "excore" region is important to utilities for topics which are not normally considered in typical reactor physics analyses, such as dosimetry, material degradation, and

This tool is widely recognized as the most advanced commercia power reactor simulator available today. Four current applications using this new capability, performed in conjunction with the Tennessee Valley Authority (TVA) and Duke Energy, have

been demonstrated (A. Godfrey et al. 2018), including:

- Watts Bar Nuclear Unit 1 (WBN1) Cycles 1-15, Vessel Fluence (Figure 4)

- Shearon Harris Downcomer Attenuation

- WBN1 Cycles 1-3, Coupon Irradiation

-WBN1 Cycle 8, Subcritical Refueling Monitoring

\section{NuScale SMR Test Stand for Crud}

A collaborative test for the application of VERA to the NuScale

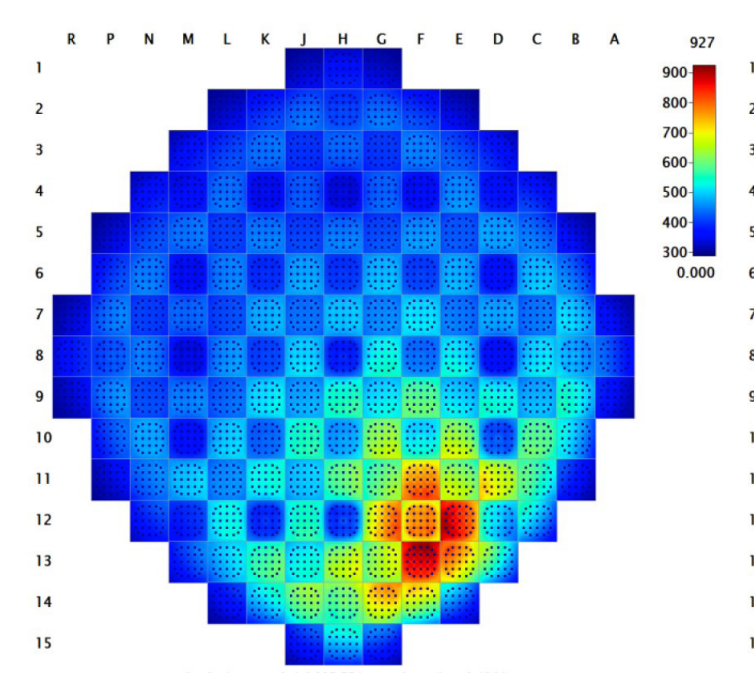

Figure 3. VERA detailed power distribution for the AP1000 at the limiting DNB condition (hotzero power [HZP] RIA)

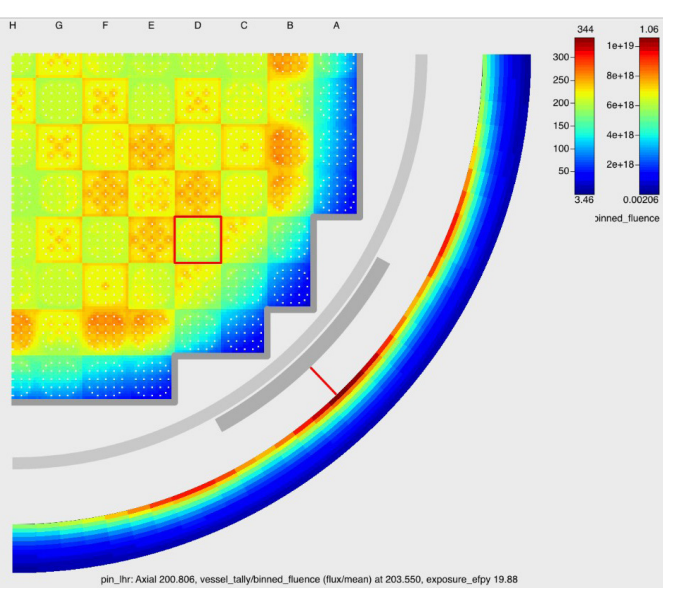

Figure 4. Watts Bar Nuclear Unit 1 (WBN1) Cycle 8 therma neutron flux and accumulated vessel fluence 
SMR design was completed in FY18. This was an exceptional opportunity for CASL to apply VERA capabilities to a new
reactor concept in support of the nuclear industry. reactor concept in support of the nuclear industry. The goal
of the test stand was to assess crud behavior for the NuScale reactor core which is impacted by flow driven by natural circulation, as shown in Figure 5 .

Based on comparison with Monte Carlo reference solutions, VERA has a demonstrated capability to accurately model the nuclear performance of the NuScale core, including the steel
block reflector $(T$. reactor characteristics identified differences from large PWRs that could impact crud formation. These differences include a lower coolant flow rate, as well as an iron-rich crud source operating PWRs. As no operational data yet exist, sensitivity analyses were performed with respect to model parameters to gain increased understanding of design crud deposition, including the impact of such terms as the spacer grid pressur lockage coefficien

\section{Coupling of DOE and NRC Codes to Support Accident-}

In FY18, a collaborative effort was initiated to support evaluathis of advanced M\&S codes in a regulatory environment. To with TRACE, the NRC system analysis code, was performed The goal was to demonstrate the MOOSE multi-apps approach for the coupling of independent codes, with a focus on mapping data transfers between codes, preservation of conserved quantities based on differing code discretization A first demanstration of the coupling was performed contro AWR station blackout in anticipation of a FY19 milestone for simulation of a large-break loss-of-coolant accident (LBLOCA) with ATF. Figure 6 displays the coupling approach, referred to as the Comprehensive Reactor Analysis Bundle (CRAB), that will serve as a potential model for future linking of additiona

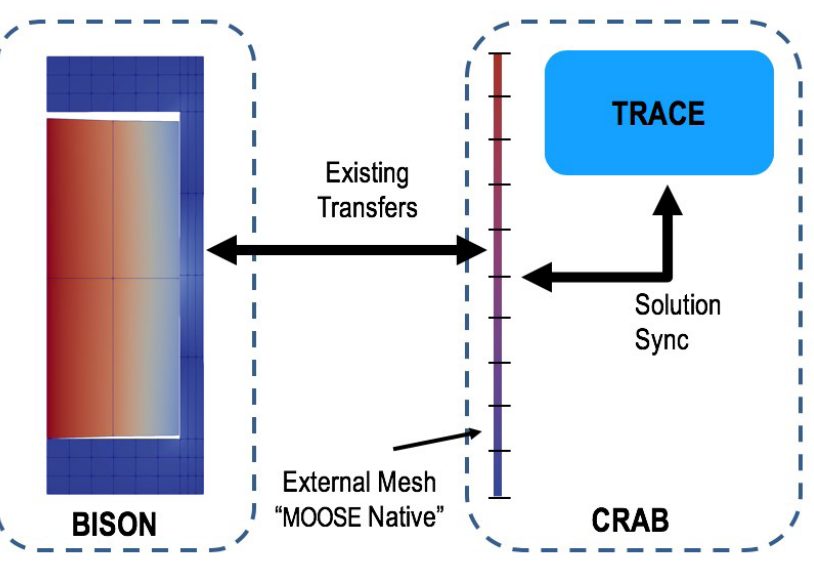

Figure 6. Coupling approach for BISON and TRACE (NRC code) coordination of personnel from the nuclear industry, academia,

\section{CASL ORGANIZATION AND OVERALL METRICS}

CASL research, development and deployment is performed by partner organizations, as well as personnel from contributing partner organizations. Periodic review and feedback on CASL performance and direction is provided by the CASL Board of Directors, the CASL Industry Council, and the CASL Science Council. These organizations have successfully demonstrated that ane stional laboratorles can dive the development of innovative gies to the private sector.

As shown in Figure 7, CASL is organized according to six technical focus areas that are supported by integrators for each CASL and development (R\&D) needs in each of the separate fields of Fuel Materials and Chemistry, Radiation Transport Methods, and
Thermal Hydraulics Methods. The Physics Integration focus area is responsible for coupled multiphysics. The Verification and Validation Implementation and Advanced Modeling Application (AMA) focus areas address technology deployment and ensure that the the nuclear industry. In addition, a separate CASL education program provides for CASL knowledge transfer and integration of CASL tools into the academic environment.

At the end of FY18, several organizational changes were implemented, as listed below:

- Dr. David Kropaczek, formerly the Chief Scientist, replaced Dr. Jess Gehin as the Director.

- Dr. Jason Hales replaced Dr. Richard Martineau, who had replaced Dr. Jim Wolf as the Deputy Director.

- Dr. Scott Palmtag assumed the position of Chief Technologist, a new position that replaces the role of Chief Scientist. This is in recognition of the emphasis placed on technology transfer to industry during the final years of CASL.

- Mr. Robert St. Clair replaced Mr. Scott Thomas as the Chair of the Industry Council.

- Dr. Patrick Mattie replaced Dr. Adam Hetzler as the acting Lead of the Verification and Validation Implementation focus area.

- Dr. Ben Collins replaced Dr. Kevin Clarno as the Lead of the Physics Integration focus area.

- Dr. Tara Pandya replaced Dr. Tom Evans as the Deputy Lead of the Radiation Transport Methods focus area.

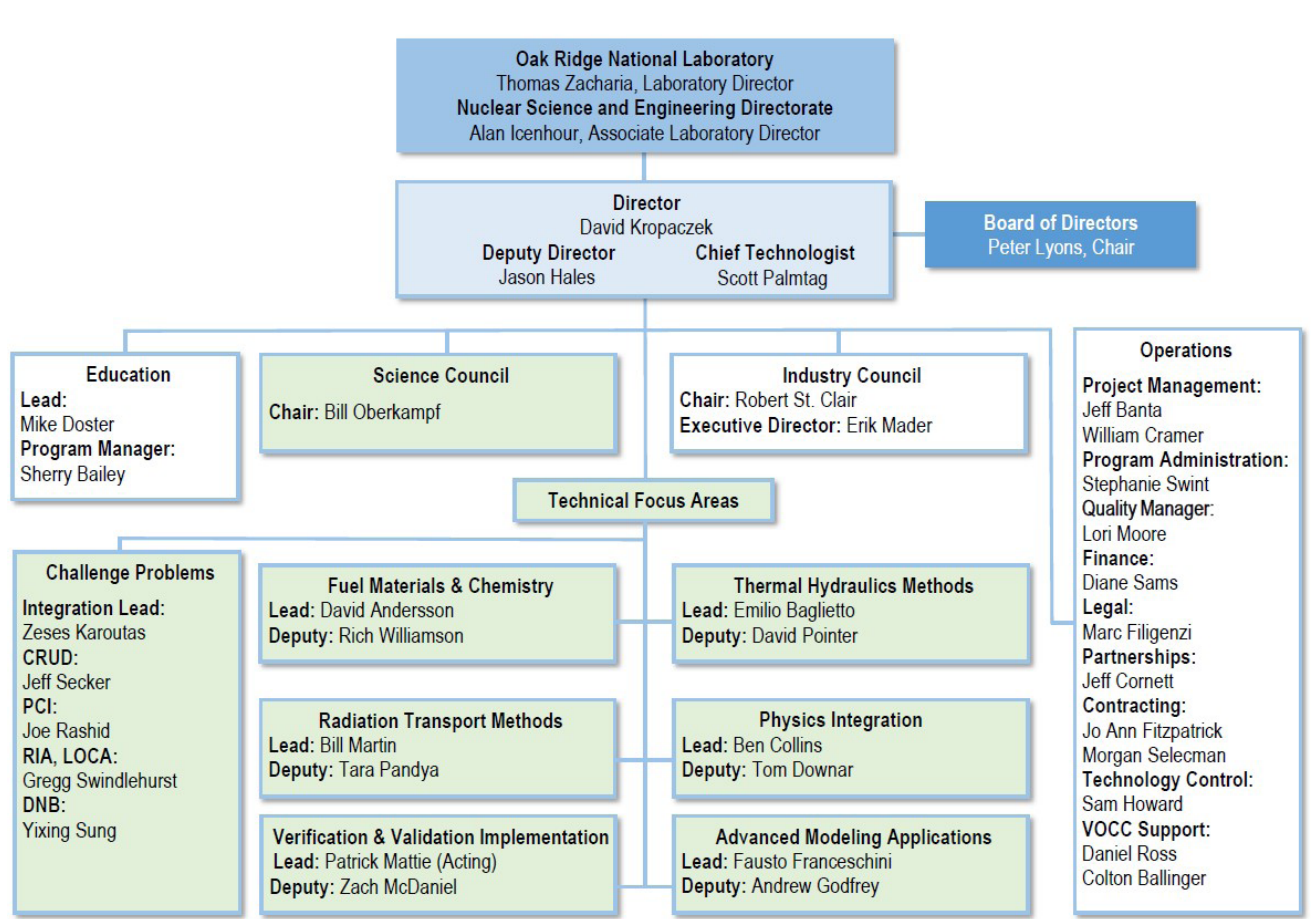

Figure 7. The CASL organization 


\section{The CASL organization}

Key metrics illustrating the success of the CASL team include the number of CASL programmatic and technical reports issued, the number of VERA license distributions, The 1 summarizes the program's technical output during FY18 including publca

tions, technical reports, invited talks, and VERA licenses issued.

Table 1. Summary of CASL technical output through FY18

\begin{tabular}{|c|c|c|}
\hline & FY18 & TOTAL \\
\hline VERA licenses & 108 & 191 \\
\hline Journal articles & 75 & 366 \\
\hline Conference papers & 54 & 604 \\
\hline Invited talks & 17 & 853 \\
\hline Technical reports & 45 & 494 \\
\hline Milestone reports & 186 & 1,227 \\
\hline Programmatic reports & 25 & 368 \\
\hline
\end{tabular}

The total CASL program costs for FY18 were \$19.6M, with \$15.1M for technical activities, $\$ 2.5 \mathrm{M}$ for program management and operations, and $\$ 1 \mathrm{M}$ for subcontracting, overhead, and taxes. Part 3 of this report provides additional cost and budget details.

The FY18 taxpayer investment in CASL produced a wide range of M\&S advances that are detailed in a comprehensive set of milestone reports. These reports document the technical progress CASL is making in the development of models and the application of VERA

\section{THE FUTURE OF CASL}

CASL is funded to continue research in FY19, with significant work planned on the remaining challenge problems. Guidance will be provided by CASL's Industry Council, CASL proposal and renewal application, as reflected in the following end-state vision for the program:

By the end of the CASL operational period, CASL will have successfully developed and deployed advanced M\&S technologies that can be used with confidence to solve the CAS challenge problems and address future nuclear energy industry challenges, emerging issues, and evolving opportunities.

Beyond FY19, a plan is being developed to establish a nuclear energy M\&S program that integrates the CASL and Nuclear Energy Advanced Modeling and Simulation (NEAMS) programs. Furthermore, the VERA Users Group (VUG) continues to evolve and will represent an additional means for industry support and access to VERA.

\section{PART 2: SCIENCE AND ENGINEERING}

\section{PROGRESS AND IMPACT}

CASL R\&D, driven by a focus on solutions for the CASL challenge problems, has advanced the state of the art with respect to predicting the operational behavior of the currentwh inter

The research performed within CASL is reviewed by an independent Science Council thit includes two representatives for each focus area. Science Counci monbers meet planning and review meetings, and once during the fall joint Industry Council and Science Council meeting. The Science Council provides an annual report to the CASL Director on its review activities.

\section{DEVELOPMENT AND ADVANCEMENT OF VERA}

VERA is a collection of integrated simulation tools that together allow for steadystate and transient analysis of the full range of physical processes that affect nucle resolution for reactor analysis down to level of individual fuel rod componted pellet, clad). The VERA code suite, depicted in Figure 8, provides direct, fully coupled solutions for core-wide neutronics, thermal-hydraulics, fuel thermomechanics, and chemistry. This full coupling allows for feedback to be resolved between the different physics phenomena. The fuel performance code in VERA's BISON provides cladding integrity estimates during a fully coupled core simulation and is also extensible to sion of the continous the extension of the VERA simulation to all reactor components beyond the reactor core and can provide the neutron fluence levels on the reactor's pressure vessel or at the excore detectors.

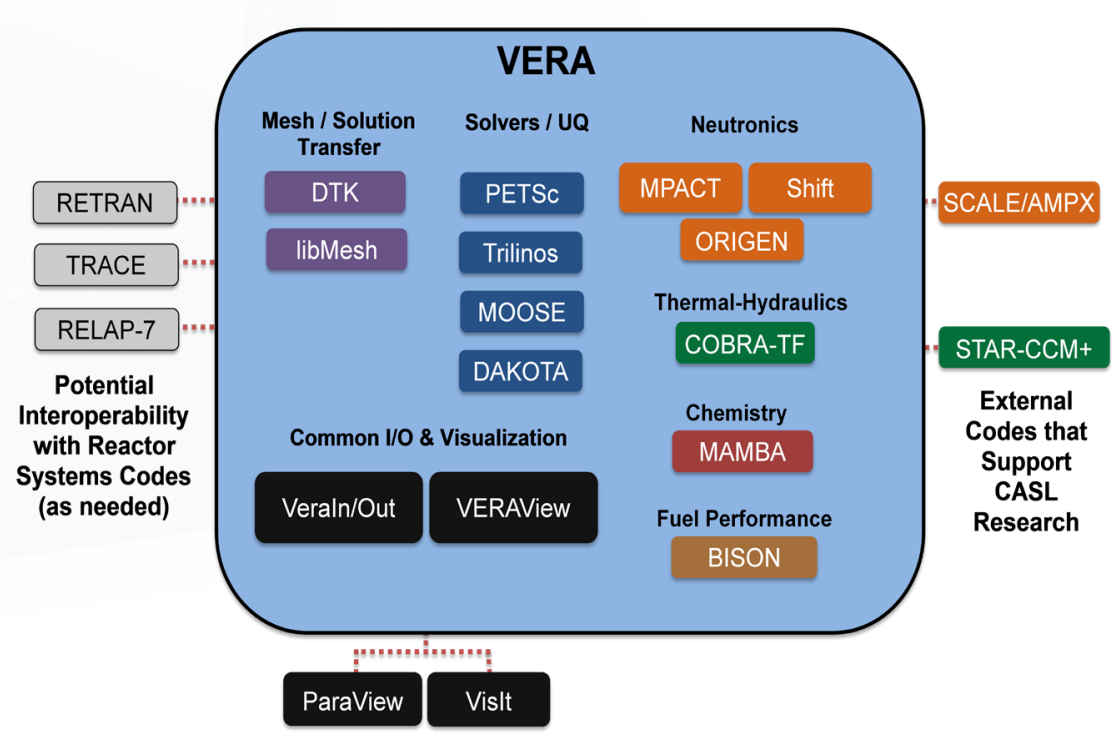

Figure 8. The VERA code suite 
The VERA user interface, VERAIn (A. Godfrey and R. Lee 2017), provides a single common geometry model to each of the underlying physics codes, including the excore compogence between codes. The VERA visualization tool, VERAView, provides the analyst with the capability to view simulation results such as the accumulated vessel fluence, as shown in Figure 9.

In FY18, VERA development continued to shift focus from R\&D to development and deployment (D\&D). Of primary importance is addressing the needs of the VERA end users with respect to the following goals:

- Increased confidence in code predictions

- Improved efficiency and robustness of software performance through verification

validation and uncertainty quantification activities

- Improved usability

- Education and workforce training

Success is achieved when solutions are provided based on science and engineering, contributing value through their impact on the curent

tions, fuel costs)

To this end, highlights of associated activities that were completed in FY18 supporting these goals include:

- Improvement of crud modeling in terms of inclusion of new chemical species, mechanistic species transport, a new, robust, stable internal kinetics solver, treatmen of ultrasonic cleaning, and crud shuffling with fuel assemblies across refueling cycles (B. Collins et al. 2018)

Finalization of the CFD two-phase closure models, including validation of DNB predictive capability against NMVG and MVG experiments (E. Baglietto et al. 2018)

- Completion of targeted improvements to the MOOSE framework and the BISON fuel performance code to improve usability through improved robustness and reduced calculation times (C. Permann et al. 2018)

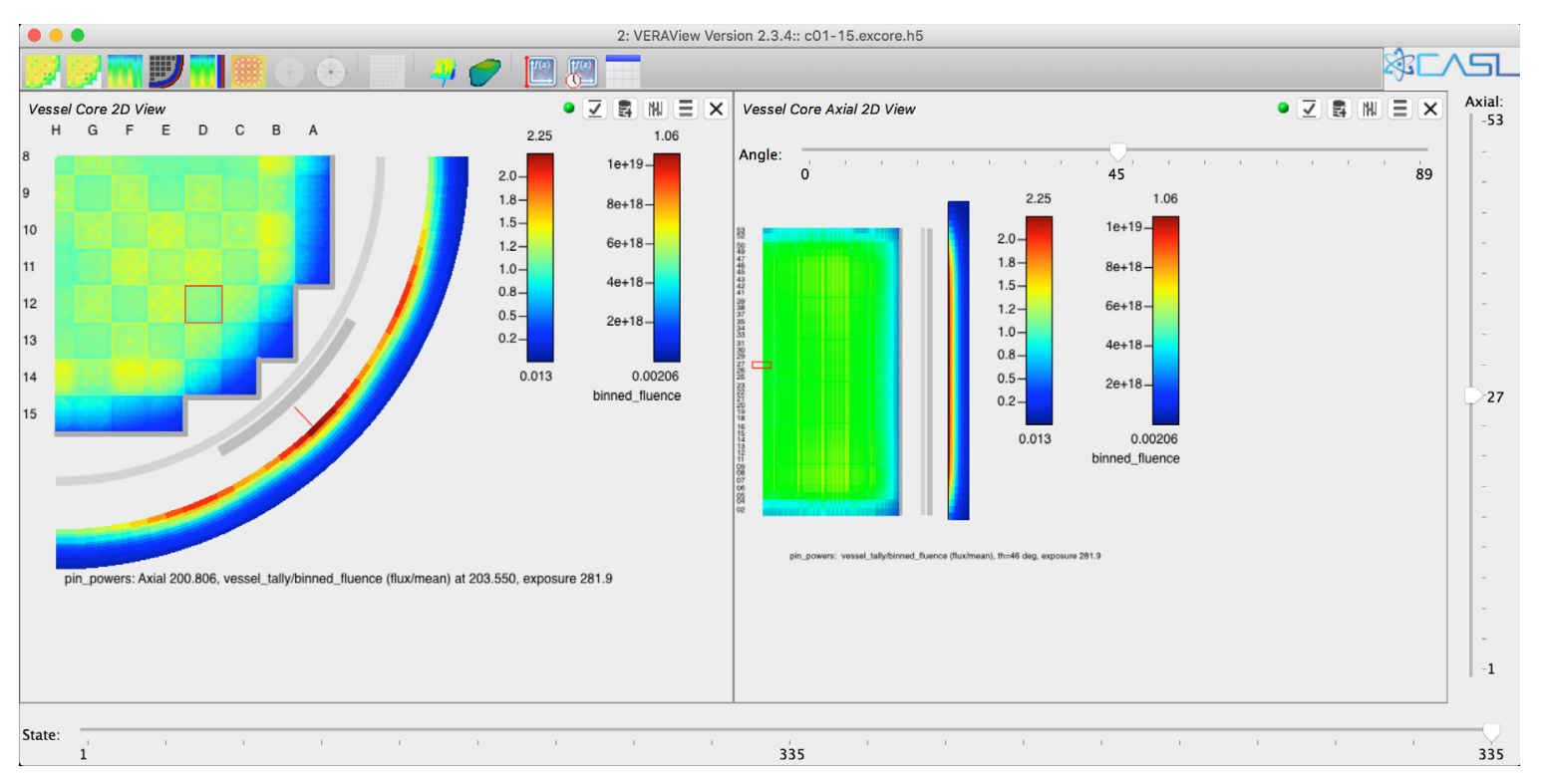

Figure 9. Example of VERAView vessel fluence calculation visualization
- Development of the ROTHCON methodology for CFDinformed subchannel based on the reconstruction of the CTF code and its application to the CILC challenge problem (R. Salko et al. 2018)

- Demonstration of the VERA transient RIA capability for the AP1000 reactor and validation against Special Power Excursion Reactor Test (SPERT) tests for the reactor core response and the CABRI and Nuclear Safety Research Reactor (G Swindlehurst 2018)

- Development, application, and validation of the fully - Dever et al. 2018)

- CFD closure modeling for two-phase annula flow and validation against BWR Full-Size Fine annular flow and (BFBT) experiments (Agostinelli 2018)

- Development of models for loss-of-coolant accidents (LOCAs) including modeling of high burnup fuel the role of hydrogen, radial and axial fuel relocation, and validation of the BISON fuel performance capability against LOCA experiments (B. Spencer et al. 2018)

- Improvements in VERAView to support user applications including RIA, CILC screening, and excore analysis (S. Ray et al. 2018)

-Workshop on code verification, solution verification, validation and uncertainty quantification for the CASL codes

(MPACT, CTF, BISON, MAMBA, and VERA)

- CASL maturity assessment update for each of the CASL codes based on the Predictive Capability Maturity Mode (PCMM) (C. Jones et al. 2018)

As VERA has matured, the software development and release process has become more stable. Every six months, at the start of each plan of record, a new candidate for release is establishe newest features can be used, and bugs or limitations can be identified and addressed before distribution outside of CASL. Each release includes developments from $R \& D$ milestones that were accomplished. Table 2 provides the VERA release schedule and new capabilities. Versions $3.7,3.8$, and 3.9 were released and provided to program.
Table 2. VERA releases

\begin{tabular}{|c|c|c|}
\hline Version & Release Date & New Capabilitites \\
\hline VERA 3.7 & Nov 2017 & $\begin{array}{l}\text { - Shift coupling in VERA } \\
\text { - Non-source code } \\
\text { distribution } \\
\text { - Support for modeling } \\
\text { combustion engineering } \\
\text { and SMR plants } \\
\end{array}$ \\
\hline VERA 3.8 & April 2018 & $\begin{array}{l}\text { - Transient VERA for RIA } \\
\text { - Inline fuel performance in } \\
\text { VERA for PCI } \\
\text { - Updated comprehensive } \\
\text { verification and validation } \\
\text { (v\&V) report for VERA }\end{array}$ \\
\hline VERA 3.9 & Sep 2018 & $\begin{array}{l}\text { - CADIS incorporated into } \\
\text { Verashift } \\
\text { - Inclusion of CTF Fuels } \\
\text { - Increased testing } \\
\text { environments }\end{array}$ \\
\hline
\end{tabular}




\section{CASL CHALLENGE PROBLEMS}

VERA is being developed to analyze real-world reactor problems. The CASL industry partners identified a set of high-priority challenge problems during formation of the problems is

\section{PROGRESS ON CRUD CHALLENGE PROBLEM}

Over the past several years, VERA has evolved to include several new components, including the ability to model the impact of crud on operating PWRs. CASL reports in FY18 (B. Collins et al. 2018) documented the improvements to the MAMBA code package which predicts the growth of the crud layer, the evolution of the thermochemistry over time inside the crud layer, and ultimately the precipitation of lithium tetraborate into the cru layer resulting in a power shift to the bottom of the core. Along with MAMBA improvethermal-hydraulic feedback in MAMBA, a model for B-10 depletion in the crud layer, the capability to shuffle and remove crud deposits from previous cycles, and improvements to the mass balance to capture the nickel particulate in the coolant, which is the leading driver of crud deposition.

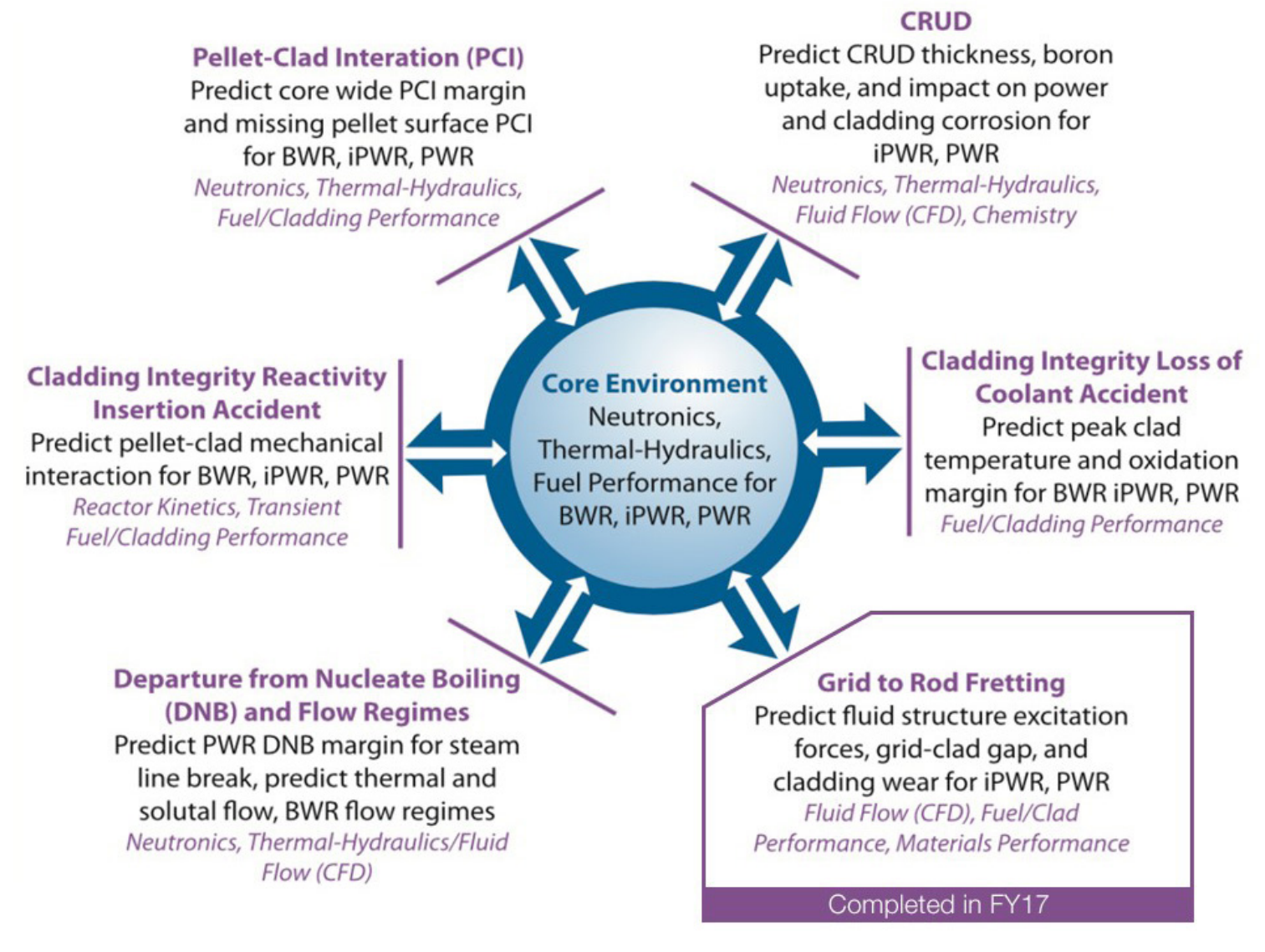

Figure 10. Summary of the CASL challenge problem scope
An initial sensitivity study and calibration process was developed and applied on WBN1, Cycle 7, by varying key components of the crud models, including impacts on the growth region. Using these th the crud chimneys, and the liquid carryover through the chimney marked well against the mariables, an appropriate combination was obiation of variables was then used in cycle 6 to confirm that the calibration worked well across multiple cycles. It is noted that the need for calibration is a fundamental aspect of the MAMBA development, as no experiments exist at reactor operating conditions that would allow for direct measurement of the crud model's unknown parameters. In addition, there is extremely high uncertainty in the crud source term (i.e., nickel and iron coolant concentrations) whic is specific to each operating reactor and depends on the characteristics of the primary
coolant system components. However, rigorous calibration approaches based on Bayesia methods have been investigated within CASL and have been shown to be applicable for MAMBA. To this end, a new calibration methodology was developed based on the use of measured operating plant data (axial offset and flux maps), experimental loop data, and post irradiation examination of crud scrape data. Calibration will be performed using a set of measured data obtained across multiple reactors and operating cycles that includes cycles with and without CIPS. The calibration process will not only be able to provide values eters. These uncertainties will then be used in an uncertainty analysis of VERA-predicted quantities of interest such as crud thickness (important to CILC), boron mass (important to CIPS), and axial offset as a function cycle depletion.

PROGRESS ON THE DNB CHALLENGE PROBLEM

The main objective of the FY18 efforts was to finalize the CFD closure models with the goal of predicting surface effects on the wall boiling up to the critical heat flux (DNB first-principle based formultion for two-phase flow phenomena which includes the CASL delivery of new experimental data to define and assess its formulation. The focus has been in three key areas:

High resolution experiments with varying surface characteristics for DNB model development

- Completion and assessment of closure models for GEN-II heat partitioning representation

Advancement and assessment of the GEN-II DNB method, including surface effects

The results demonstrate a fundamental advancement in the technology and the ability to include the effect of surface characteristics on the boiling predictions from first principle bases. Figure 11 shows the boiling curve surfaces characterized by differences in surface roughness, morphology, and wettability. The ability to predict rod surface effects within two-phase CFD will allow for modeling of rod aging, as well as ATF fuel concepts.

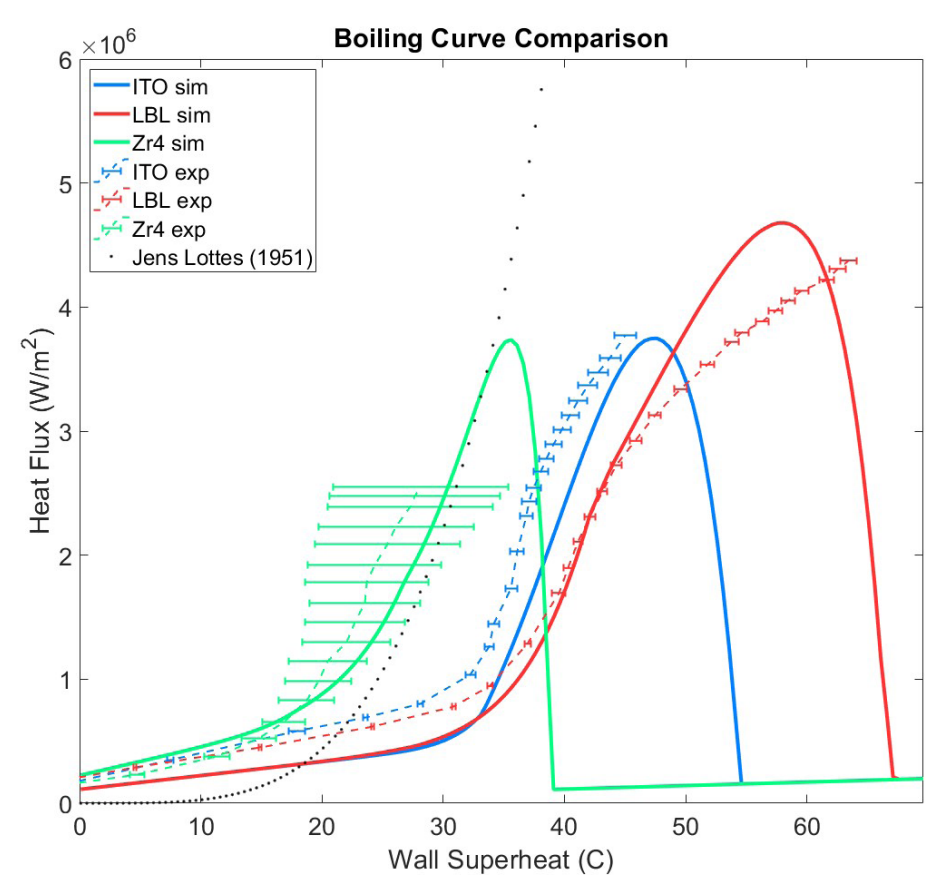

Figure 11. Boiling curve comparison and DNB detection for different surfaces 


\section{PROGRESS ON THE PCI CHALLENGE PROBLEM}

Activities in $\mathrm{FY} 18$ for the $\mathrm{PCl}$ challenge problem focused on improvements to coupling BISON within VERA and the analysis of fuel performance for flexible power operations, also known as load following events. A new, fully coupled fuel performance and core simulaprovide the fuel temperatures for neutronic feedback in the MPACT power distribution calculation. With BISON 1.5D, this calculation is performed for every fuel rod in the core with two-way coupling, and it provides for a fast, robust calculation. To evaluate cladding stresses to assess PCI risk, one-way coupling allows for execution with BISON 2D (r-z and $r$-theta) and BISON 3D utilizing the VERA detailed power histories.

CASL worked with Westinghouse and Exelon through the University of Illinois UrbanaChampaign (UIUC) test stand to evaluate the integrated VERA and BISON capability to model nominal operation and flexible power operations for the Byron and AP1000 plants. Additional work focused on understanding the thermomechanical-chemical state of the closure/rooding fission gas release as a function of power changes, and PCI stresses related to thermal expansion and swelling.
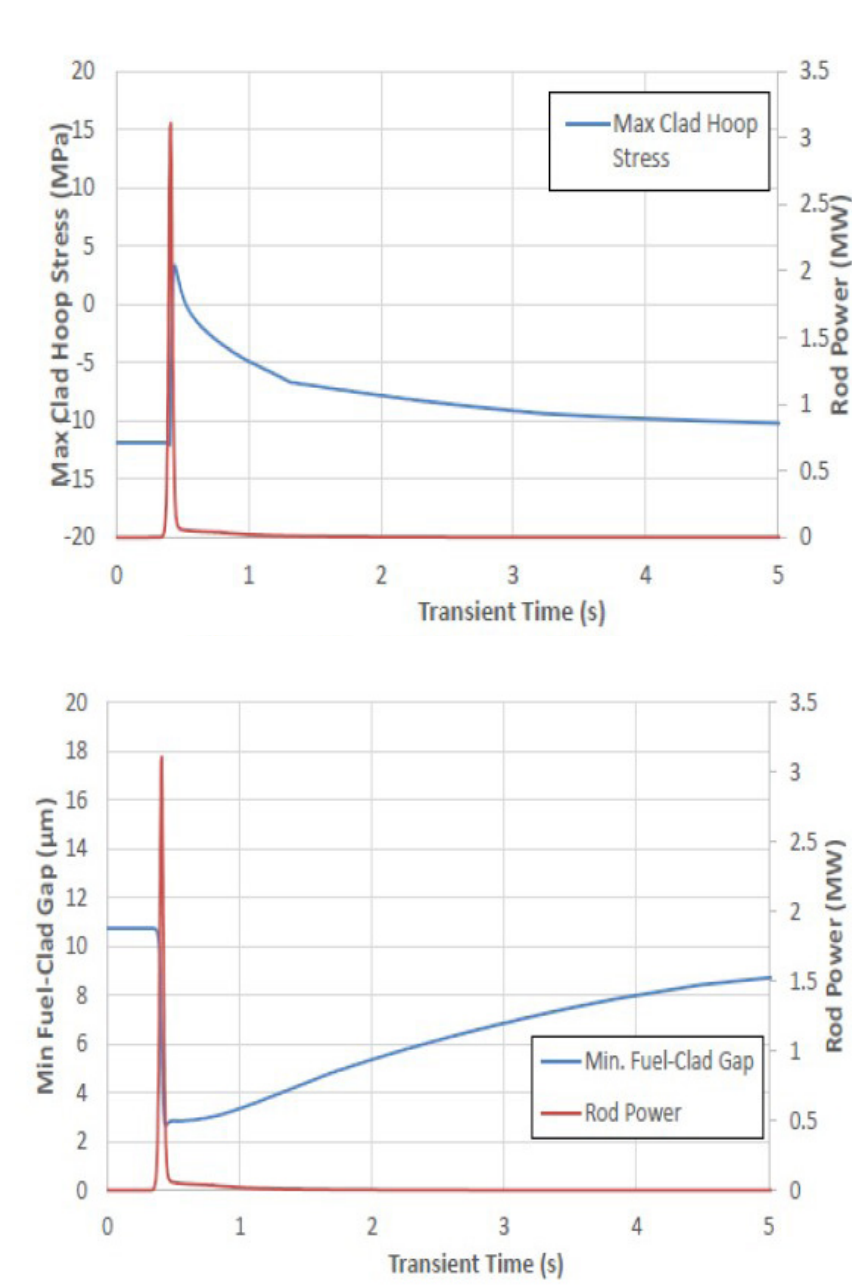

Figure 12. BISON calculated cladding hoop stress and gap width evolution for the AP1000 RIA simulation

\section{PROGRESS ON RIA CHALLENGE PROBLEM}

RIA-related code development was completed in FY18, with most of the work focused on validation and demonstration activities. The validation of VERA and BISON to RIA neutronic and fuel rod thermal-mechanical test data includes a comprehensive selection of tests from available domestic an transient VERA validation and the CABRI and NSRR tests for transient $\mathrm{VERA}$ BSON validation.
B

A large-scale VERA analysis was performed for the AP1000 RIA a the fully coupled, pin-resolved, whole-core modeling capabilities of VERA in an industry production environment. This included a real-world problem formulation considering conservative assumptions, as would normally be performed for an NRC licensing application. Examples of such assumptions include selecting conditions to maximize the ejected rod worth and deposited energy in the fuel rods strating a high-fidelity RIA modeling capability to support high-burnup fuel according to NRC DG-1327 (G. Swindlehurst 2018).

For the RIA BISON analysis, the highest power and burnup fuel rods were selected for detailed analysis based on the transient power history. Fine resolution 2D-RZ axisymmetric modeling using 15 radial and 1,000 axial mesh resolution was performed. Figure 12 displays the BISON results for the showing the evolution of the cladding hoop stress and minimum fuel-clad gap as a function of transient time for the fuel rod with maximum rod energy deposition.

The VERA simulations required 25.8 hours of execution time computationally intensive, it is within reach for industry use computationally intensive, it is within reach for industry use.
The CASL RIA M\&S capabilities are expected to be applied the industry resolution of regulatory issues associated with on 6,840 processors on the INL Falcon cluster. While this is

when performing reference calculations, determining margins to regulatory figures-of-merit, evaluating RIA test results, and providing simulation results to fill gaps in the RIA experimental testing database. They may also be used to replace or augment licensing meth-
odologies. The progress to date shows that transient licensing applications with VERA can be realized, including those involving ATF.

\section{PROGRESS ON LOCA CHALLENGE PROBLEM}

FY18 activities for the LOCA challenge problem focused on robustness, performance improvements, and validation against additional experiments. Recent BISON model developments to address convergence issues include improvements to the mechanical contact model and smeared cracking model. The $\mathrm{UO}_{2}$ creep model (B. Spencer et al. 2018) was implemented to more realistically represent for burst release that represents the effect of grain-boundary sepation due to microcracking. as well as a model for high burnup structure (HBS) formation and the associated grain size evolution. Improvements to evolving material interfaces that are prevalent in nuclear fuel, such as the oxide layer and central void formation, have been implemented using the extended finite element method (XFEM) (W. Jiang and B. Spencer 2018).

The new LOCA validation cases that were simulated with BISON for this work in FY18 include:

- Oak Ridge National Laboratory (ORNL) separate-effects cladding burst tests

- Argonne National Laboratory (ANL) integral experiments

- Halden Instrumented Fuel Assembly (IFA)-650.9 integral fuel rod test, which includes significant axial fuel relocation

The BISON results for the ANL time-to-burst tests which are based on internally pressurized furnace-heated fuel rods comprised of Zr-2 cladding and fresh fuel.

BISON models are now available for all the main phenomena that characterize fuel rod behavior during LOCAs, including models for high-temperature steam oxidation of Zircaloy cladding, crystallographic phase transformation of Zircaloy, high-temperature cladding work will focus on fuel and material development for ATF, continued effort to improve robustness and performance, expansion of the LOCA validation database, and demonstration of the LOCA application for ATF using the coupled TRACE and BISON CRAB system performed in collaboration with the NRC.

Table 3. BISON-calculated burst test results for ANL experiments (OCL-5, OCL-8 and OCL-11)

\begin{tabular}{|c|c|c|c|}
\hline & OCL-5 & OCL-8 & OCL-11 \\
\hline $\begin{array}{c}\text { Measured burst } \\
\text { temperature (K) }\end{array}$ & 1,006 & 1,039 & 1,026 \\
\hline $\begin{array}{c}\text { Predicted burst } \\
\text { temperature (K) }\end{array}$ & 1,057 & 1,057 & 1,057 \\
\hline $\begin{array}{c}\text { Burst time difference } \\
\text { (pred-meas) (s) }\end{array}$ & +10.2 & +3.6 & +5.6 \\
\hline
\end{tabular}




\section{PART 3: END USER IMPACT AND NUCLEAR} INDUSTRY ENGAGEMENT

CASL's shift from R\&D to development and deployment (D\&D) coincided with an increased emphasis on industrial applications and user engagements within CASL. This shift has been accompanied by continued inprovements in the computational A high focus on software V\&V is now evident to stakeholders, and with increased confidence in the software, the interactions and collaborations with industrial end users continues to increase. This development has also led to an increased number of external installations of VERA, several professional training workshops, and formatio of the VUG. This trajectory of success will continue through FY18 and beyond the

clusion of the CASL initiative.

The significant increase in applications and model development in FY18 was driven by the following goals.

- Develop the VERA user base through direct collaboration with VERA early adopters from industry organizations (utilities, vendors, NRC) on applications of interest

- Support implementation and deployment of VERA into industry workflows (e.g. core design process)

- Develop and execute VERA organizational communication plans in conjunction with early adopters to internally promote VERA success

- Build the portfolio of VERA high-value applications and communicate externally about those successes through participation in industry meetings

- Continue industry outreach by engaging industry on VERA addressable issues

through user trainings and workshops

- Expand the VERA user base through proactive solicitation, mentoring, and

training of new users and organizations

\section{APPLICATION OF VERA TO OPERATING PLANTS}

In FY18, VERA applications were extended to several existing plants and to some new designs. These applications represent a broad spectrum of design and operating

conditions for the curnt and future operating heet. The analyses performed also represent a key component of the VERA V\&V plan, with improved confidence in the robustness of the software's physics, geometry, and n
VERA relates to solving the CASL challenge problems.

Overall, CASL has expanded its applications to 21 reactors with simulation of 152 operating fuel cycles. As shown in Figure 12, this represents nearly the full spectrum advanced LWR reactor designs such as the NuScale SMR.

Not only is VERA being used as a benchmark tool for previous cycles of operation, but also as a reference solution in the mode of making "blind predictions" for recent May 2016, and the Sanmen Nuclear Power Station in China. Sanmen 1 and 2 are the first implementations of the advanced AP1000 reactor developed by Westinghouse: Unit 1 achieved initial criticality in June 2018, and Unit 2 followed suit in August 2018 VERA predictions for both WBN2 and Sanmen showed excellent agreement with global and local measured data. The recent Sanmen results show close agreement ficient $(0.5 \mathrm{pcm} / \mathrm{deg}-\mathrm{F})$, and maximum and minimum rod worth $(3.9 \% \mathrm{pcm}$ and $-1.6 \% \mathrm{pcm}$. The excellent VERA agreement confirms the Westinghouse design values for the AP1000 first core.

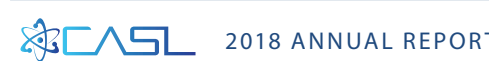

\section{INDUSTRY USE OF CASL TOOLS}

CASL supported five test stands in FY18 that focused on specific applications of VERA:

- Framatome: modeling of core follow and crud formation in Davis-Besse Cycle 15 - work is underway

- University of Illinois/Exelon: evaluation of fuel duty under load follow conditions as related to PCI for Byron - completed, with followup work moved to AMA activities in FY18

- Westinghouse Electric Company (WEC): analysis of WEC SiC and U3Siz ATF concepts with BISON (joint with NEAMS) - completed

- NuScale: analysis of crud in SMRs under natural circulation, including an investigation of integral reactor crud sources

- NRC: application of CASL tools to ATFs - initiated in FY18

Industry interactions are critical for providing plant data, providing subject matter expertise, determining software needs and requirements, comparing VERA to existing codes, and expanding the VERA end user base. In addition to work done with the test stands, CASL continues to collaborate with industry partners on the use of VERA. Additional industry engagements in FY18 included collaboration
with Arizona Public Service, Duke Energy, the Electric Power Research Institute (EPRI), the Naval Nuclear Lab, SCANA, Southern Nuclear, and TVA.

As a result of these collaborations, several additional high-value applications were defined and demonstrated, most notably applications involving the new excore (coupled VERA and Shift) capability. CASL collaborated with TVA on the simulation of WBN1 for 15 successive fuel cycles, with the vessel fluence calculated from Shift. Because of the parallelization provided by Shift and the optimized

Table 4. VERA reactor analysis by plant, cycles, reactor design and fuel type

\begin{tabular}{|c|c|c|c|}
\hline & Plant & Cycles & Reactor and Fuel Type \\
\hline 1 & AP100 & $1-5$ & W Gen III+ 2-loop $17 \times 17 \mathrm{XL}$ \\
\hline 2 & Byron 1 & $17-21$ & W 4-loop $17 \times 17$ \\
\hline 3 & Callaway & $1-12$ & W 4-loop $17 \times 17$ \\
\hline 4 & Catawba 1 & $1-9$ & W 4-loop $17 \times 17$ \\
\hline 5 & Catawba 2 & $8-22$ & W 4-loop $17 \times 17$ \\
\hline 6 & Davis-Besse & $12-15$ & B\&W $15 \times 15$ \\
\hline 7 & Farley & $23-27$ & W 3-loop $17 \times 17$ \\
\hline 8 & Haiyang & 1 & W Gen III+ 2-loop $17 \times 17 \mathrm{XL}$ \\
\hline 9 & Krško & $1-3,24-28$ & W 2-loop $16 \times 16$ \\
\hline 10 & NuScale & $1-8$ & SMR \\
\hline 11 & Oconee 3 & $25-30$ & B\&W $15 \times 15$ \\
\hline 12 & Palo Verde 2 & $1-16$ & CE system $8016 \times 16$ \\
\hline 13 & Sanmen & 1 & W Gen III+ 2-loop $17 \times 17 \mathrm{XL}$ \\
\hline 14 & Seabrook & $1-5$ & W 4-loop $17 \times 17$ \\
\hline 15 & Shearon Harris & Surrogate & W 3-loop $17 \times 17$ \\
\hline 16 & South Texas 2 & $1-8$ & W 4-loop $17 \times 17 \mathrm{XL}$ \\
\hline 17 & Three Mile Island & $1-10$ & B\&W $15 \times 15$ \\
\hline 18 & V.C. Summer & $17-24$ & W 3-loop $17 \times 17$ \\
\hline 19 & Vogtle 1 & $9-15$ & W 4-loop $17 \times 17$ \\
\hline 20 & Watts Bar 1 & $1-18$ & W 4-loop $17 \times 17$ \\
\hline 21 & Watts Bar 2 & $1-2$ & W 4-loop $17 \times 17$ \\
\hline
\end{tabular}




\section{Average Fluence Rate By Cycle}

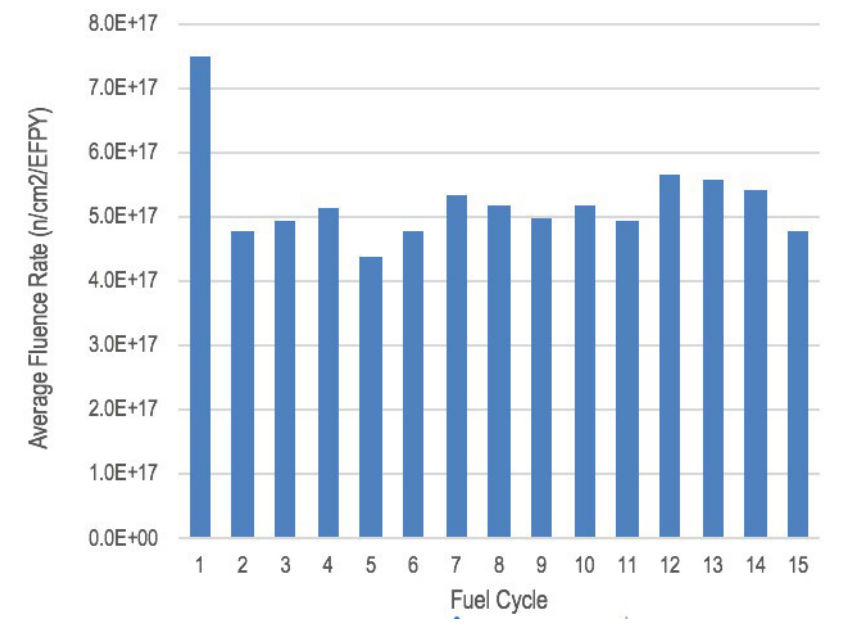

Figure 13. VERA fluence by cycle for Watts Bar 1

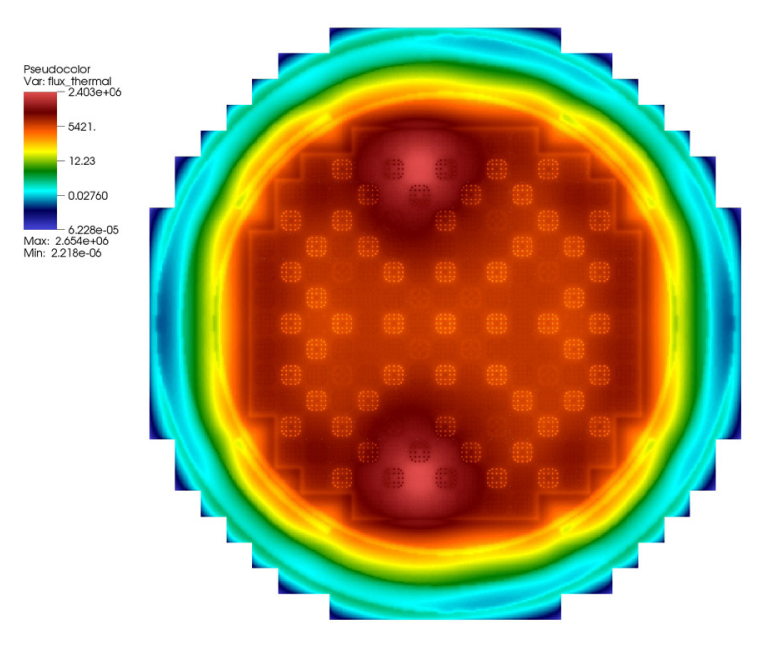

Figure 14. S
fully loaded coupling within VERA, a minimal increase in compute runtime
was demonstrated. From the user's perspective, this demonwas demonstrated. From the user's perspective, this demon-
strated that a material fluence may be obtained directly as part of a VERA simulation. This contrasts with the current industry practice, which requires separate code packages to be run. These efforts often involve high levels of approximation, including assumed reactor source terms and assumed dimensionality shown in Figure 13 , there is a significant variation of fluence between fuel cycles, ranging from -14 to $+11 \%$. This reflects the differences in reload design strategy, such as that due to fuel placement on the core periphery. A best-estimate fluence using cycle-specific source terms can reduce uncertainties, identify excess margins tolfetimelimit, andinform

CASL collaborated with Duke Energy on the use of VERA-Shift to analyze the excore detector response with respect to reactor downcomer coolant density which influences the detector signa industry methods and were shown to be consistent with existing modeling methodologies.

A separate application of VERA-Shift to excore detectors was performed in collaboration with TVA. This application subcritical, source-driven problem that includes the modeling of activated secondary source rods important to the source signal. The placement of secondary sources is important to the excore detectors' ability to identify potential core misloadings during the fuel reload and shuffe sequence. As shown in Figure 14, of influence for the two secondary sources. Initial comparison against measured data demonstrated excellent agreement with the predictions of the excore detector response. Further validation will continue in $\mathrm{FY} 19$ and will include modeling the partially loaded core shuffle sequence.

A summary of VERA's industry applications performed by Westinghouse in partnership with CASL was provided in a publication at the TOPFUEL 2018 meeting held in Prague in September 2018 (Figure 15). The paper, "Industry Use of CASL Tools" (S. Ray et al.

- AP1000 reactor control rod ejection accident

- DNB evaluation of PWR steamline break event

- PWR DNB margin improvement

- CFD-based thermal-hydraulic applications

- Fuel rod applications of CASL tools

- Advanced analysis of crud

While many of these applications had been reported on previously within CASL, the paper focuses on specific industry

applications of CASL technology, as well as focusing on the "value ctrum of CASL capabilities and potential benefits to industry.

\section{CASL TECHNOLOGY TRANSFER}

Transfer of CASL-developed technology is a primary goal during the final phase of CASL. Technology transfer includes knowledge transfer and access tor tools via VERA user licenses. The mechanisms for knowledge transfer include:

- Direct collaboration and engagement with industry partners on industry applications (as discussed previously)

- Industry Council meetings

- VERA trainings

- Application topic workshops

- VERA Users Group

- CASL Education Program

VERA licenses have been issued to individual users based on test and evaluation (T\&E) licenses. To date, 158 individual VERA licenses have been issued. These are non-replicated licenses and do not include multiple counting of incremental license versions. The 40 organizations represented include 14 industry organizations, 11 national laboratories, and 15 universties - a balanced mix of users ranging from in the classroom, R\&D, and the industry environment. In addition to the T\&E licenses, commercial use licenses are being developed to allow for use of VERA in the offering of products and services for nuclear industry organizations.

\section{CASL INDUSTRY COUNCIL}

The CASL Industry Council provides programmatic oversight and periodic review of CASL activities from the perspective of the nuclear power industry. Council members providers, and independent software vendors. The CASL Industry Council includes 24 organizations, as shown in Figure 17. It is an important mechanism for engaging potential end users, providing feedback on CASL direction, and initiating data exchanges or collaboration on specific projects.

In 2018, two CASL Industry Council meetings were held, including a joint meeting with the CASL Science Council in October 2018, and an independent CASL Industry Council meeting in April 2017 (Figure 18). Increasingly, CASL Industry Council meetings include presentations and feedback on VERA results from non-CASL members, demonstrating successful applications of VERA outside CASL's work scope. In FY18, the following

- "Harris Nuclear Plant Excore NI Detector Response" was presented by Hersche Smith of Duke Energy (with Eva Davidson and Tara Pandya of ORNL), showing VERA's ability to accurately simulate excore detector response.

- "Discussion on Possible Future Benefits and Administrative Challenges" was presented by Robin Jones of Southern Nuclear, with a focus on the potential

- "Davis-Besse Cycle 15 CIPS Analysis with VERA - Interim Results" was presented by Greg Hobson from Framatome, demonstrating the measured data of VERA 3.6

- "Westinghouse BISON Accident Tolerant Fuel (ATF) Test Stand" was presented by Paul Kersting of WEC, illustrating an assessment of BISON capabilites for applica-
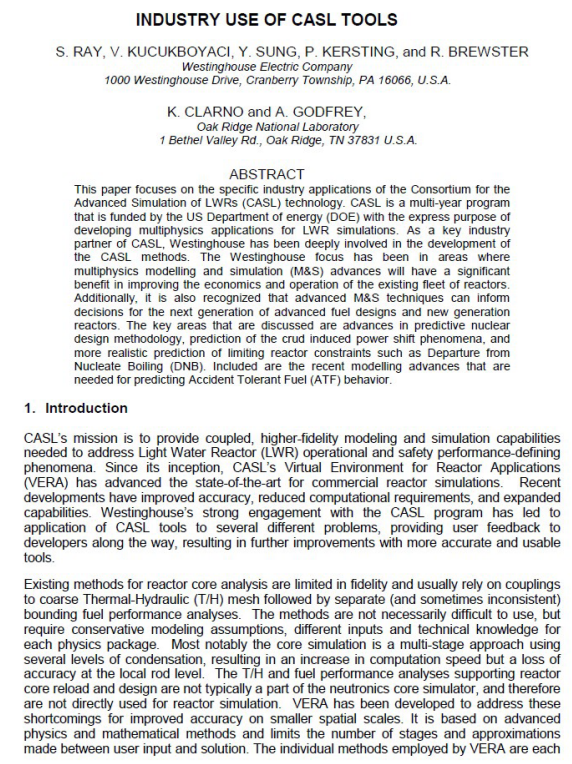

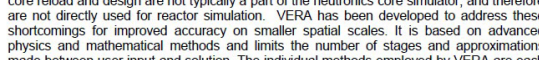

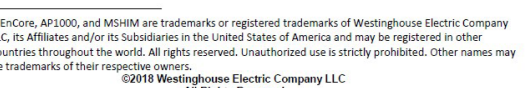

Figure 15. TOPFUEL 2018 publication on
"Industry Use of CASL Tools"

\section{VERA User Licenses Issued}

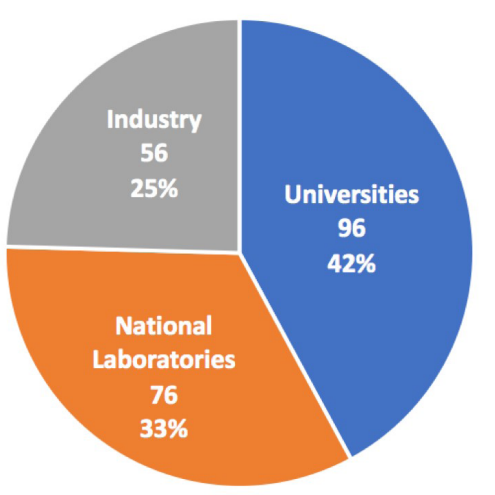

158 VERA individual licenses

40 organizations

14 industry

11 national laboratories

Figure 16. VERA licenses issued to

individuals by organizatio 
One of the major actions from the CASL Industry Council was the solicitation of an industry survey on potential in-house organizational use of VERA and the organization interest level regarding the use of VERA in targeted application areas. The application areas included the CASL challenge problems
(crud, PCI, DNB, RIA, and LOCA), excore applications (EXC), analysis for ATF, and use of VERA as a reference calculation survey questions asked whether the organization hat the survey questions asked whether the organization had access
to the computing resources needed for use of CASL tools. The survey results are summarized in Table 4 . Organizations that provided data to CASL as part of the industry collaboration are also indicated in the survey results.

The survey found that VERA applications for crud, excore, and use of VERA as a reference calculation have the highest levels of interest. There was also interest in ATF from 4 respondents, which included the fuel vendors Westinghouse and Framatome, EPRl and Duke. The remaining ingerest came from 1-3 respondents-nearly all of which are nuclear utilities-lack the computing resources needed to run VERA: this may be a perceived barrier for use of VERA in the future. There was a clear message that access to advanced Modsim capabilities by US utilities is a barrier to adoption. Access to computing resources is therefore a top priority that will be addressed by

Figure 17. CASL Industry Council member organization

\section{VERA USERS GROUP}

The VERA Users Group (VUG) has the mission to provide sustainability for VERA after CASL by providing software maintenance and

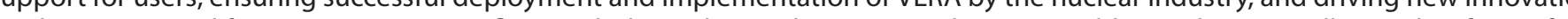

The first VUG meeting was held in conjunction with the April 2018 CASL Industry Council meeting in Asheville, North Carolina. The UUG established the following set of objectives:

- Facilitate technology transfer of software to industry

- Provide software control, maintenance, and support

- Provide critical, shared high-performance computing (HPC) resources

- Provide user training classes

- Coordinate topical workshops on industry use cases

- Facilitate communication among members and promote best practices

- Establish process for user software license agreements

Expand space for VERA in terms of high-value applications

The VUG will ensure the long-term success of CASL by sustaining the use of VERA after the program is completed. The VUG is currently comprised of CASL Industry Council members who are interested in obtaining the CASL codes directly or who desire access to the mechanisms, computer allocations, technical support and training.

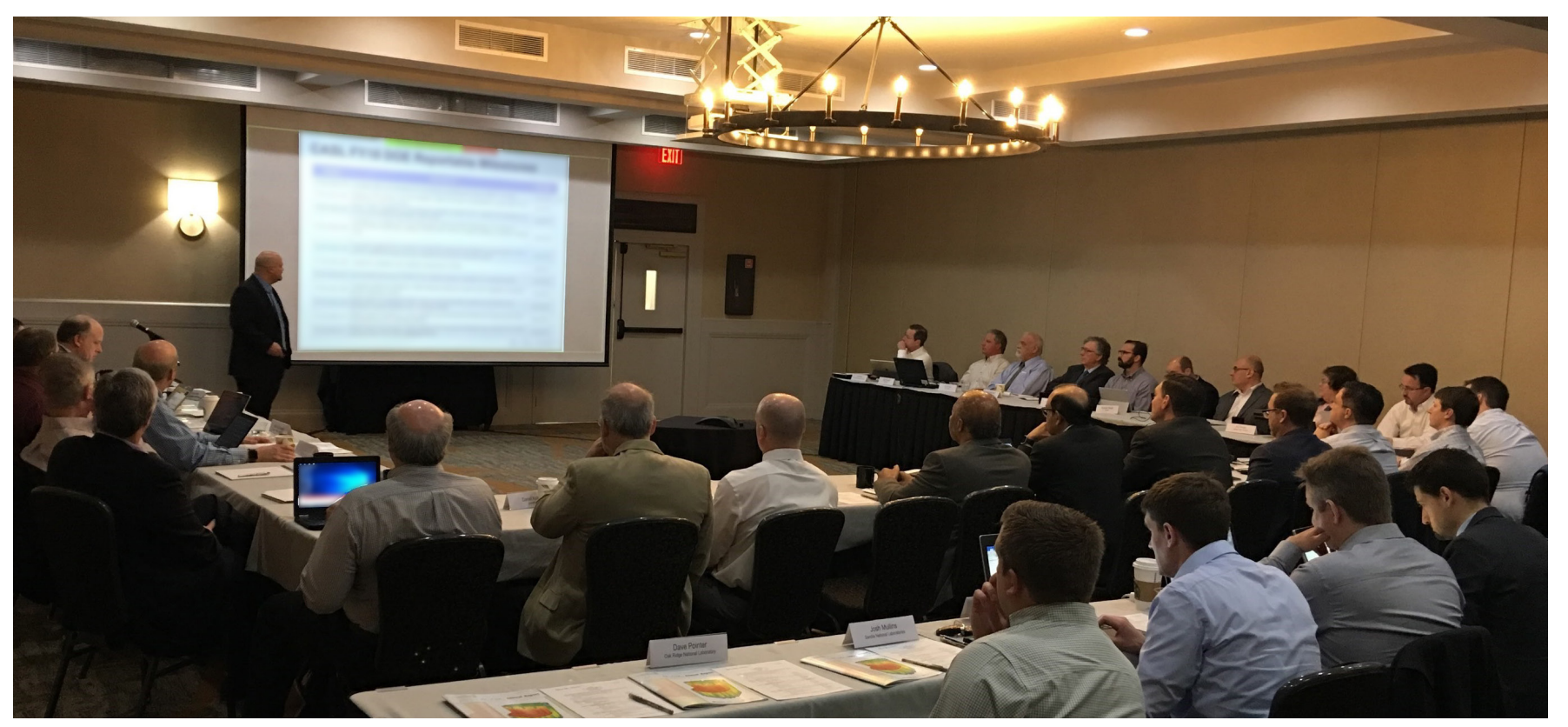

Figure 18. CASL Industry Council meeting, Asheville, North Carolina, April 10-11, 2018
Table 5. Industry Council survey responses on VERA use

\begin{tabular}{|c|c|c|c|c|c|c|c|c|c|c|c|}
\hline Entity & $\begin{array}{c}\text { Provided } \\
\text { Data }\end{array}$ & $\begin{array}{c}\text { Will use } \\
\text { VERA }\end{array}$ & $\begin{array}{c}\text { Has } \\
\text { computer }\end{array}$ & CRUD & EXC & RIA & PCI & DNB & LOCA & ATF & REF \\
\hline APS & $\checkmark$ & & & $\checkmark$ & & & & & & & \\
\hline Duke & $\checkmark$ & $\checkmark$ & & $\checkmark$ & $\checkmark$ & & & & & $\checkmark$ & \\
\hline Exelon & $\checkmark$ & & Computing & & & & $\checkmark$ & & & & $\checkmark$ \\
\hline JSI & $\checkmark$ & $\checkmark$ & resources & & & & & & & & $\checkmark$ \\
\hline SCANA & $\checkmark$ & $\checkmark$ & needed & & & & & & & & $\checkmark$ \\
\hline Southern & $\checkmark$ & $\checkmark$ & & $\checkmark$ & & $\checkmark$ & & & & & \\
\hline TVA & $\checkmark$ & $\checkmark$ & & $\checkmark$ & $\checkmark$ & & & & & & $\checkmark$ \\
\hline EPRI & $\checkmark$ & $\checkmark$ & $\checkmark$ & $\checkmark$ & $\checkmark$ & & $\checkmark$ & & & $\checkmark$ & \\
\hline Framatome & $\checkmark$ & $\checkmark$ & $\checkmark$ & $\checkmark$ & $\checkmark$ & & & & & $\checkmark$ & $\checkmark$ \\
\hline NNL & $\checkmark$ & $\checkmark$ & $\checkmark$ & & & & & & & & $\checkmark$ \\
\hline NuScale & $\checkmark$ & $\checkmark$ & $\checkmark$ & $\checkmark$ & $\checkmark$ & & & $\checkmark$ & & & $\checkmark$ \\
\hline PNNL & $\checkmark$ & $\checkmark$ & $\checkmark$ & & & & & & & & $\checkmark$ \\
\hline Rolls-Royce & & $\checkmark$ & $\checkmark$ & & & & & & & & $\checkmark$ \\
\hline Westinghouse & $\checkmark$ & $\checkmark$ & $\checkmark$ & $\checkmark$ & $\checkmark$ & $\checkmark$ & $\checkmark$ & $\checkmark$ & $\checkmark$ & $\checkmark$ & $\checkmark$ \\
\hline
\end{tabular}




\section{CASL TRAINING AND WORKSHOPS}

In FY18, two major information/training events were held: a two-day training on June 5-6, 2018 in Corvallis, Oregon, at NuScale Power and a workshop on February 19, 2018 at ORNL.

During the NuScale training session, approximately 10 reactor core designers and engineers successfully completed the hands-on training using their own computing cluster. Each one-day class provided a brief CASL overview, a description of VERA methods, and presented a hands-on guide to running problems with VERA common input, progressing from small, single, 2 D fuel lattice problems up to whole-core calculations. To ensure training success, a quick-start guide for running cases on Binford was provided in advance to all class participants, so they were able to ensure computer access and functional scripts prior to training. A photo of the Corvallis class open exchange on the use of VERA for non-CASL applications.

The Excore Radiation Transport workshop aimed to provide an opportunity for CASL staff (methods developers and analysts) to meet with industry expents and shat experts and potential users. CASL can be better positioned to perform research and deliver a product with advanced capabilities that is useful to the commercial nuclear power industry. Presenters at this workshop included five industry partners—Shift Dominion, Westinghouse, Enercon, NuScale, and Duke Energy-and two presentations were made by ORNL developers on ADVANTG methods. Workshop topics included:

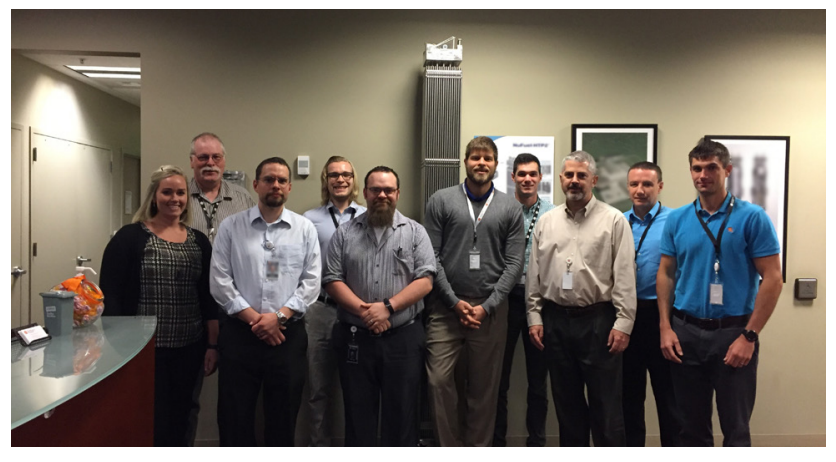

Figure 19. VERA Training at NuScale in Corvallis, Oregon

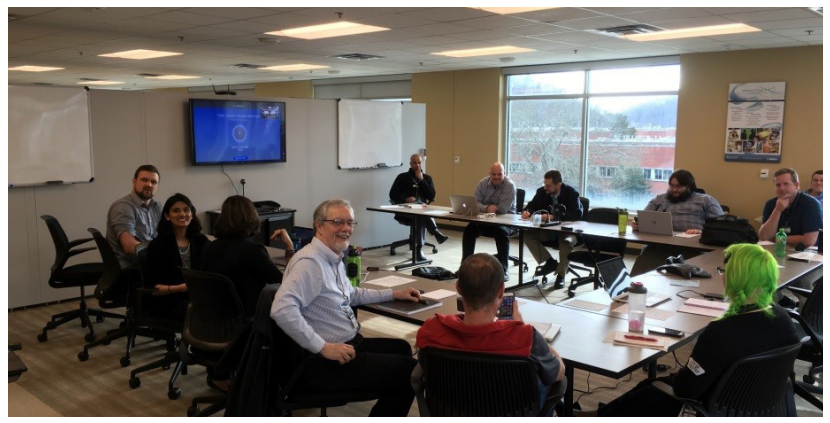

Figure 20. Excore neutron transport calculations
Inverse count rate ratio (ICRR) behavior without secondary sources

- Vessel fluence, component degradation, and plant aging

- Drywell material activation, heating, and dose assessments

- Excore detector design, placement, and response

- Downcomer attenuation during cooldown events

ENGAGEMENT WITH THE NRC potential areas of collaboration. In FY18, CASL initiated a formal edge and expertise in the use of advanced M\&S tools developed The focus on ATF is in anticipation of licensing applications related to advanced ATF concepts such as $\mathrm{U}_{3} \mathrm{Si}_{2}$ fuel that will be submitted in the future for NRC review. CASL collaborated with the NRC to develop a program plan (Figure 21) with the following scope:

Position the NRC to be able to evaluate CASL software for ATF concepts, including VERA tools access, training, and
knowledge transfer

Perform development, uncertainty quantification, and documentation of BISON fuel performance models for ATF concepts

Generate a set of ATF benchmark progression problems to process (lattice physics / core analysis) use by the NRC for AT
Since its inception, CASL has engaged with representatives from the NRC to provide status on CASL progress and to identify engagement specifically to allow the NRC to evaluate the use of pated outcome of the collaboration is to enhance NRC knowlby DOE. To provide the highest value to the NRC and CASL, a identify limitations of the traditional two-stage analysis

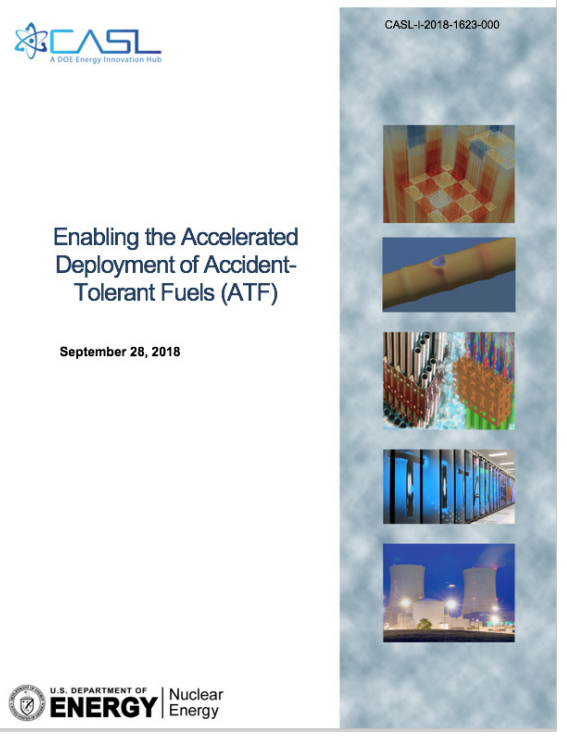

Figure 21. CASL and NRC collaboration

program plan

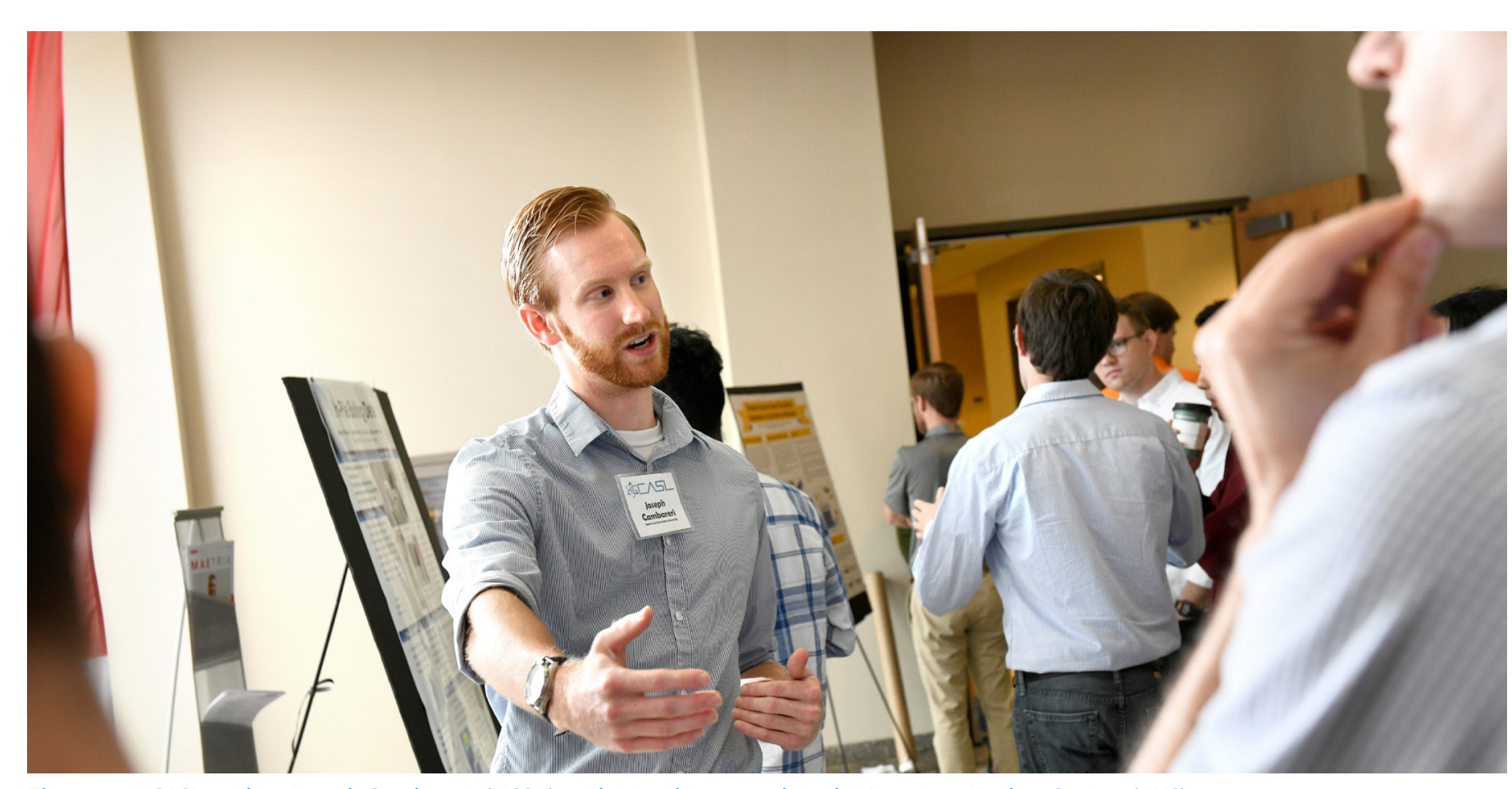

2. CASL student Joseph co

poster session
- Demonstrate the CRAB capability (TRACE and BISON coupling) for an ATF concept to support fuel integrity assessments during PWR LOCA transients (building on Priminary work completed in FY18) nvestigations

Develop a report on the application of VERA to longer term ATF concepts for PWR steady-state methods

Collaboration with the NRC is modeled on the CASL partnerships that have been successful in the advancement and adoption of technology by industry. Specific milestones were developed in conjunction with the NRC based on feedback and technic exchanges between DOE and NRC technical staff. Milestone progress will be tracked, with periodic review and feedback reported during FY19.

\section{CASL EDUCATION PROGRAM}

The mission of the CASL Education Program is to educate the next generation of LWR designers, scientists, and nuclear power professionals. The objectives of the program undergraduate and graduate course curricula and (2) to encourage the transfer of CASL technologies to industry users. Activities supporting these goals include:

- CASL Undergraduate Research Scholars program

- CASL Summer Research Experience for Undergraduates (REU)

- Summer internships at CASL partner laboratories

- Development of new courses at participating universities

- CASL Institute/Certificate Program

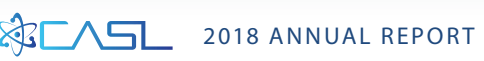

- Establish a CFD test stand at the NRC to enable two-phase fuel assembly flow

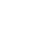


The CASL Undergraduate Research Scholars program, now in its sixth year, matches top students at North Carolina State University (NCSU) with CASL faculty mentors. During the $2017-2018$ academic year, five scholars engaged in projects with four different faculty 17 are now attending graduate school, and 6 have completed graduate degrees. For the eighth year, the CASL Education Program participated in the ANS Student Conference to promote CASL research opportunities and to highlight student research activities. In April 2018, the conference was held in Gainesville, Florida. Five CASL undergraduate research scholars presented their research at the

The CASL Education Program also supported its fourth Research Experience for Undergraduates (REU) in the summer of 2018. Dan Dubard, a student from South Carolina State University, worked with Dr. David Kropaczek at NCSU. Ms. Davis's research focused on advanced nuclear fuel designs and the use of the CASL codes with industry codes. As a demonstration of the program's success,

CASL currently has 49 students representing 4 universities active in CASL research and receiving funding. Of the 49 students, 6 are undergraduates, 4 are in graduate school, at the master's level, 36 are obtaining PhDs, and 3 are postdoctoral researchers.

The CASL Institute, which was held in August 2018, is a two-week education and training activity on VERA codes and methods that is open to university students and working professionals. In 2018, there were over 40 applicants, 22 of whom completed the course (Figure 23). The curriculum covered the CASL codes and challenge problems in lectures and hands-on projects. Students were cer

This was the third year of the CASL Institute, and it was the second year that it was held on NCSU's campus. Holding the course offsite demonstrated the ability to address issues such as export control and access to HPC resources. The success of the 2018 CASL Institute provides another model for access to VERA tools in a non-laboratory environment in the post-CASL phase.

CASL also supports a suite of summer internships at ORNL and with other partner organizations. In FY18, CASL hosted 13 summer students at ORNL from May through August. These students worked on a range of topics related to CASL R\&D:

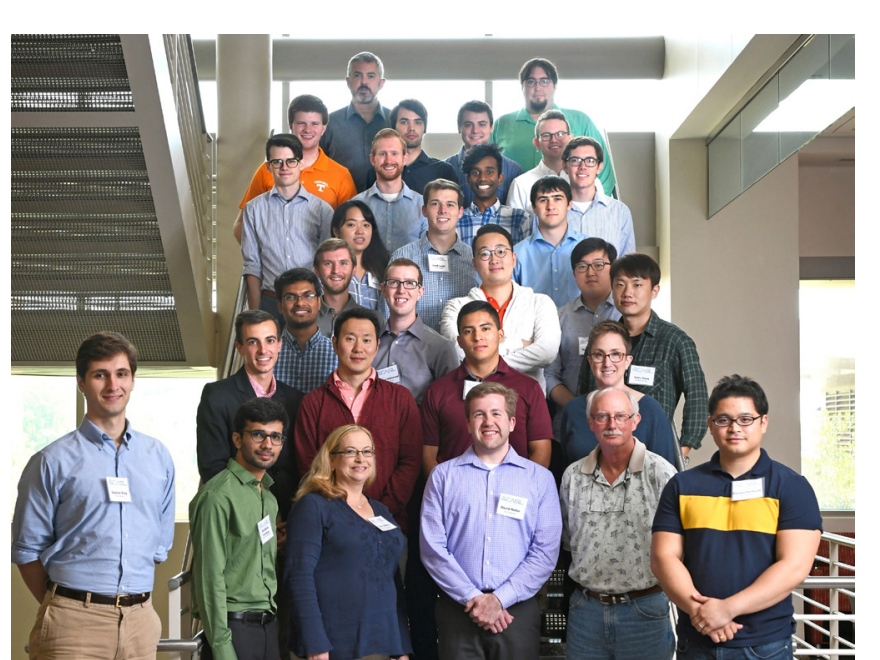

Figure 23. CASL Institute participants and faculty
- Joseph Coale (NCSU) working with Dr. William Wieselquist

- Alicia Elliot (Massachusetts Institute of Technology) working

- Austin Ellis (NCSU) working with Dr. Kevin Hamilton

- Tarek Ghaddar (Texas A\&M University) working with Dr.

Benjamin Collins

- Alec Golas (University of Massachusetts Lowell) working with

Dr. Thomas Evans

Jacob Gorton (Penn State University) working with Dr.

Benjamins Collins

Will Gurecky (University of Texas at Austin) working with Dr.

Stuart Slattery

- Shane Henderson (NCSU) working with Dr. Kevin Clarno

- Byoung-Kyu Jeon (University of Michigan) working with Dr. Kang Seog Kim

- Daniel O'Grady (University of Illinois Urbana-Champaign)

working with Dr. Andrew Godfrey

- Aaron Reynolds (Oregon State University) working with Dr.

Shane Stimpson

- Xinyan Wang (University of Michigan) working with Dr.

Shane Stimpson

- Xingang Zhao (Massachusetts Institute of Technology)

working with Dr. Robert Salko

\section{PART 4: RETURN ON FY18 TAXPAYER} INVESTMENT

The CASL leadership and operations team continued working to ensure that the program produces a strong return on taxpayer investment and that funding provided by DOE-NE is carefully managed. The primary measure of return on investment is outcomes for the nuclear industry. Regarding financial management, CASL's work is executed through contracts established by ORNL and is issued to CASL partner organizations. CASL's finance officer monitors the CASL contracts and tracks financial reports through monthly reports and quarterly financial teleconference calls. CASL has also continued plan rep for sustang

\section{FY18 FINANCIAL PERFORMANCE}

A summary of the budget and spending for FY18 funding is presented in Table 5. The total funding includes carryover from FY17, as well as FY18 funding received from DOE. As shown, approximately $80 \%$ of the FY18 CASL costs (i.e., total costs minus subcontracting overhead and taxes) were associated with R\&D work, and the remainder was associated with management, operations, and computing and collaboration infrastructure. Unspent FY18 funding will be carried over and allocated to FY18 activithat. The perentage of the smaller percentage related to Verification and Validation Implementation (VVII) represents a decision to integrate the $V \& V$ activities directly into the other focus areas as means to increase focus.

\section{FY18 Focus Area Distribution}

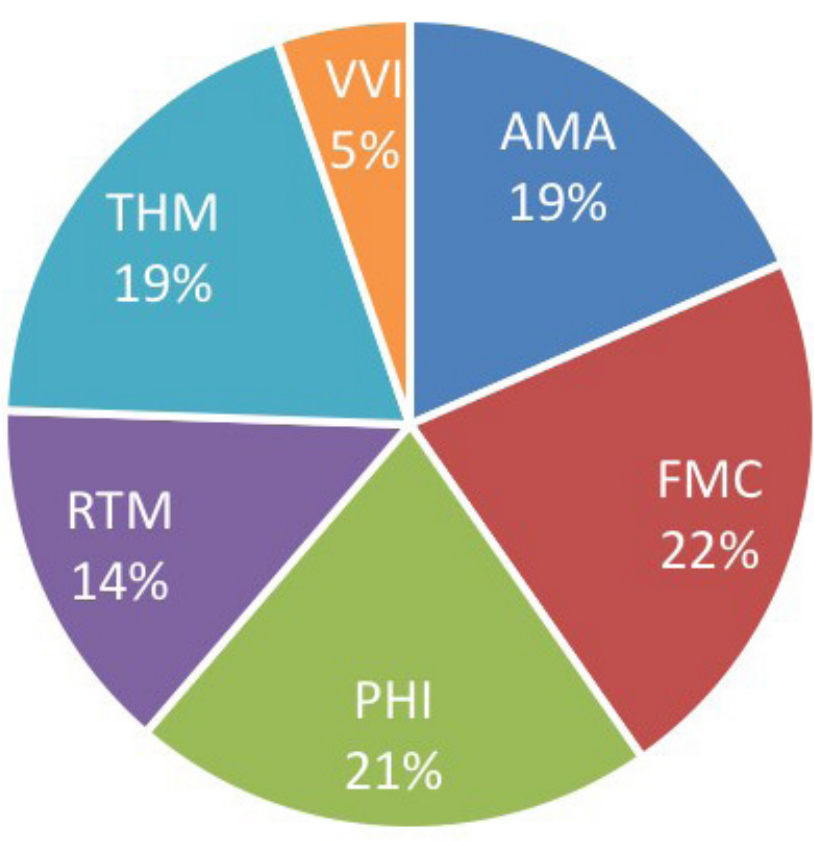

Figure 24. FY18 budget distribution by focus area 


\section{MILESTONE COMPLETION}

CASL's R\&D activities are organized through an annual planning process into a set of milestones and an execution plan. A total of 239 milestones were defined for work to be performed in excuting its scope.

Table 6. FY18 budget and cost summary

\begin{tabular}{|l|r|r|}
\hline & FY18 Budget & \multicolumn{1}{|c|}{ FY18 Cost } \\
\hline Technical activities & $\mathbf{1 7 , 9 0 0 , 0 0 0}$ & $\mathbf{1 5 , 1 0 6 , 9 4 9}$ \\
\hline Fuel Materials and Chemistry (FMC) & $3,903,000$ & $3,017,625$ \\
\hline Thermal Hydraulics Methods (THM) & $3,425,000$ & $2,420,898$ \\
\hline Radiation Transport Methods (RTM) & $2,554,000$ & $2,336,444$ \\
\hline Physics Integration (PHI) & $3,755,000$ & $3,669,534$ \\
\hline Advanced Modeling Application (AMA) & $3,312,000$ & $3,175,104$ \\
\hline Verification \& Validation Implementation (VVI) & 951,000 & 487,344 \\
\hline Program management and operations & $\mathbf{2 , 7 8 5 , 0 0 0}$ & $\mathbf{2 , 5 0 5 , 9 5 3}$ \\
\hline Management & $\mathbf{1 , 1 0 0 , 0 0 0}$ & $\mathbf{1 , 8 8 4 , 3 4 4}$ \\
\hline Operations & $1,685,000$ & 621,609 \\
\hline CASL Education Program and Institute & $\mathbf{6 3 2 , 0 0 0}$ & $\mathbf{3 0 2 , 3 0 0}$ \\
\hline Computing and collaboration infrastructure & $\mathbf{8 0 0 , 0 0 0}$ & $\mathbf{5 9 7 , 8 9 9}$ \\
\hline Subcontracting overhead and taxes & $\mathbf{8 5 0 , 0 0 0}$ & $\mathbf{1 , 1 7 9 , 7 5 3}$ \\
\hline Contingency/reserve & $\mathbf{8 0 , 0 0 0}$ & \\
\hline Commitment remaining & $\mathbf{N A}$ & $\mathbf{2 , 2 6 3 , 6 6 1}$ \\
(unexecuted purchase requisitions) & $\mathbf{2 3 , 0 4 7 , 0 0 0}$ & $\mathbf{2 1 , 9 5 6 , 5 1 5}$ \\
\hline Total & $\mathbf{5 , 2 6 5 , 7 2 0}$ & $\mathbf{N A}$ \\
\hline FY17 carryover & $\mathbf{5 , 0 0 0 , 0 0 0}$ & $\mathbf{N A}$ \\
\hline DOE/NRC collaboration research & $\mathbf{3 3 , 3 1 2 , 7 2 0}$ & $\mathbf{N A}$ \\
\hline Grand Total & &
\end{tabular}

\section{*Committed FY17 carryover available for FY18 scope}

*An additional \$5M funding was directed to CASL late in FY18. Because CASL had insufficient time/capacity to execute the additional scope in FY18, this funding was therefore FY18 uncosted carryover, so the additiona

\section{DOE REPORTABLE MILESTONES}

The FY18 DOE-reportable milestones are provided in Table 6. All milestones were completed and delivered on time.

Table 7. FY18DOE-reportable milestones

\begin{tabular}{|c|c|c|c|}
\hline Milestone ID & DOE Milestone & Finish Date & Reference \\
\hline FY18.CASL.001 & Complete initial crud simulations for the NuScale SMR Test Stand & Jan 2018 & T. Lange et al \\
\hline FY18.CASL.002 & $\begin{array}{l}\text { Release VERA version } 3.8 \text { to the Radiation Safety Information } \\
\text { Computational Center (RSICC) for distribution to approved users } \\
\end{array}$ & Apr 2018 & \\
\hline FY18.CASL.003 & $\begin{array}{l}\text { Deliver VERA capability for CILC, testing, documentation and to } \\
\text { AMA users }\end{array}$ & June 2018 & $\begin{array}{l}\text { B. Spencer } \\
\text { et al. }\end{array}$ \\
\hline FY18.CASL.004 & $\begin{array}{l}\text { Complete first phase of the test stand project with the NRC to } \\
\text { demonstrate a preliminary coupling of BISON with TRACE to } \\
\text { support analysis of ATFs }\end{array}$ & June 2018 & $\begin{array}{l}\text { R. Salko } \\
\text { et al. }\end{array}$ \\
\hline FY18.CASL.005 & $\begin{array}{l}\text { Completet targeted improvements to the MOOSE framework } \\
\text { and BISON fuel performance code to improve usability through } \\
\text { improved robustness and reduced calculation times }\end{array}$ & June 2018 & $\begin{array}{l}\text { C. Permann } \\
\text { et al. }\end{array}$ \\
\hline FY18.CASL.006 & Update the V\&V assessment of VERA & July 2018 & $\begin{array}{l}\text { C. Jones } \\
\text { et al. }\end{array}$ \\
\hline FY18.CASL.007 & $\begin{array}{l}\text { Demonstrate application of VERA excore radiation transport capa- } \\
\text { bility for a selected reactor }\end{array}$ & July 2018 & $\begin{array}{l}\text { A. Godfrey } \\
\text { et al. }\end{array}$ \\
\hline SL.008 & $\begin{array}{l}\text { Complete additional validation of GEN-II thermal-hydraulics } \\
\text { models for the DNB challenge problem }\end{array}$ & 18 & $\begin{array}{l}\text { G. Swindle- } \\
\text { hurst } 2018\end{array}$ \\
\hline FY18.CASL.009 & $\begin{array}{l}\text { Deliver a report on progress of CASL R\&D activities and results } \\
\text { for the RIA challenge problem }\end{array}$ & Sep 2018 & $\begin{array}{l}\text { E. Baglietto } \\
\text { et al. }\end{array}$ \\
\hline FY18.CASL.010 & $\begin{array}{l}\text { Deliver a report on progress of CASL R\&D activities and results } \\
\text { for the PCl challenge problem }\end{array}$ & 18 & $\begin{array}{l}\text { J. Rashid } \\
\text { et al. }\end{array}$ \\
\hline FY18.CASL.011 & $\begin{array}{l}\text { Deliver a report on progress of CASL R\&D activities and results } \\
\text { for CIPS challenge problem }\end{array}$ & Sep 2018 & $\begin{array}{l}\text { B. Collins } \\
\text { et al. }\end{array}$ \\
\hline
\end{tabular}




\section{CONCLUSIONS}

CASL continued to advance the VERA technology in FY18 with a shift in activities from R\&D to D\&D. The CASL tools have continued to mature as the user base has grown. This has been achieved through key accomplishments associated with progress on CASL's challeng problems, development of new VERA capabilities such as VERA-Shift, and expansion of
engagement with the nuclear industry through a growing list of new applications. Engagement with the NRC has increased through establishment of a formal collaboration program focused on ATF. The CASL education program continues to be very active, providing support to student scholars and researchers and holding the third successful CASL institute. The CASL program remains on track to fulfill its end-state vision within the final years of CASL operations. The program is making strong progress toward establishing VERA as a set tion and analysis of commercial LWRS. For FY19, the focus of CASL is on delivery of the chalenge problem solutions and technology transfer to industry. This will be achieved through an active VUG that will provide sustainability for the CASL tools well into the future.

\section{ACKNOWLEDGMENTS}

This research was supported by the Consortium for Advanced Simulation of Light Water Reactors (www.casl.gov), an Energy Innovation Hub (http://www.energy.gov/hubs) for Modeling and Simulation of Nuclear Reactors under US Department of Energy Contract No. DE-AC05-00OR22725.

An award of computer time was provided by the Advanced Scientific Computing Research (ASCR) Leadership Computing Challenge (ALCC) Program. This research used resources of he Oak Ridge Leadership Computing Facily at ORNL, which is supported by the Office of Science of the US Department of Energy under Contract No. DE-AC05-00OR22725.

This research made use of the resources of the High-Performance Computing Center at INL, which is supported by the Ofice of Nuclear Energy of the US Department of Energy under Contract No. DE-AC07-05ID14517. 


\section{REFERENCES}

Baglietto, E., M. Bucci, E. Demarly, R. Kommajosyula, and D. Pointer, Complete Additional Validation of GEN-II Thermal-Hydraulics Models for the DNB Challenge Problem, CASL-U2018-1668-000, August 2018.

Collins, B., B. Okhuysen, R. Salko, D. Andersson, S. Stimpson, T. Lange, A. Elliott, A. Wysocki, L. Gilkey, K. Epperson, and R. Smith, CASL Research and Development Activities and Results for the CRUD Induced Power Shift (CIPS) Challenge Problem, CASL-U-2018-1703-000, September 2018

Godfrey, A., E. Davidson, T. Pandya, and C. Gentry, VERA Excore Radiation Transport Applications, CASL-U-2018-1647-000, June 2018.

Godfrey, A., and R. Lee, VERAView User's Guide, CASL-U-2016-1058-001, Oak Ridge National Laboratory, August 2017.

Jiang W., and B. Spencer, BISON X-FEM Development in Support of Moving Interface CASL-U-2018-1611-000, May 2018

Jones, C., A. Hetzler, N. Dinh, P. Athe, and M. Sieger, Updated Verification and Validation Assessment for VERA, CASL-U-2018-1645-000, June 2018.

Lange, T., A. Godfrey, R. Ratnayake, K. Epperson, J. Eller, and R. Salko, Preliminary CRUD Analysis and Sensitivity Studies for NuScale SMR, CASL-U-2018-1504-000, January 2018. Lefebvre, R., M. Sieger, M. Baird, R. Lee, and K. Clarno, VERA 3.8 Release, CASL-U-201891579-000, April 2018.

Pastore, G., R. Williamson, and C. Folsom, Transient Fission Gas Behavior Modeling Developments for BISON, CASL-U-2018-1610-000, May 2018.

Permann, C., M. Bernard, D. Andrs, S. Novascone, D. Gaston, and R. Martineau, Preliminary Two-Way Coupling of BISON/TRACE using MOOSE-Wrapped Apps (BlueCrab), CASL-U-20181638-000, June 2018.

Rashid, J., W. Liu, N. Capps, J. Hales, R. Williamson, B. Spencer, and G. Pastore, Progress of (PCI) Challenge Problen

Ray, S., V. Kucukboyaci, Y. Sung, P. Kersting, and R. Brewster, Industry Use of CASL Tools,

Salko, R., S. Slattery, T. Lange, M. Delchini, W. Gurecky, E. Tatli, and B. Collins, Development of Preliminary VERA-CS Crud-Induced Localized Corrosion Modeling Capability, CASL-U2018-1617-000, June 2018

Spencer, B., R. Williamson, A. Lindsay, F. Kong, R. Gardner, J. Hales, A. Casagrande, D. Schwen, H. Chen, N. Prakash, C. Matthews, and C. Unal, BISON Improvements for Robustness and Speed, CASL-U-2018-1625-000, June 2018.

Swindlehurst, G., Development, Validation, and Demonstration of CASL Codes for the Reactivity Initiated Accident, CASL-U-2018-1646-000, August 2018.

Agostinelli, G. and E. Baglietto, BWR Closure Modeling for Annular Flow, CASL-U-2018-1841000, August 2018. 
